\title{
OPTIMAL ORDERING POLICY IN A TWO-ECHELON SUPPLY CHAIN MODEL WITH VARIABLE BACKORDER AND DEMAND UNCERTAINTY
}

\author{
Sumon SARKAR ${ }^{1, *}$ AND BibHas Chandra GiRI ${ }^{1}$
}

\begin{abstract}
The paper investigates a two-echelon production-delivery supply chain model for products with stochastic demand and backorder-lost sales mixture under trade-credit financing. The manufacturer delivers the retailer's order quantity in a number of equal-sized shipments. The replenishment lead-time is such that it can be crashed to a minimum duration at an additional cost that can be treated as an investment. Shortages in the retailer's inventory are allowed to occur and are partially backlogged with a backlogging rate dependent on customer's waiting time. Moreover, the manufacturer offers the retailer a credit period which is less than the reorder interval. The model is formulated to find the optimal solutions for order quantity, safety factor, lead time, and the number of shipments from the manufacturer to the retailer in light of both distribution-free and known distribution functions. Two solution algorithms are provided to obtain the optimal decisions for the integrated system. The effects of controllable lead time, backorder rate and trade-credit financing on optimal decisions are illustrated through numerical examples.
\end{abstract}

Mathematics Subject Classification. 90B05, 90B06.

Received March 9, 2019. Accepted January 27, 2020.

\section{INTRODUCTION}

Supply chain (SC) management is concerned with the coordination of material, information, and money along with a network of companies whose purpose is to achieve better performance. Supply chain can be classified into two categories-integrated (or centralized) and non-integrated (decentralized) supply chains. In a non-integrated supply chain each member decides based on its own policy, which can lead to inefficient decisions (Katok and $\mathrm{Wu}[21]$ ). According to Giannoccaro and Pontrandolfo [10], co-ordination strategy incentivises each supply chain member in such a way that the decisions taken jointly by the members are optimal from a centralized supply chain perspective to increase the chain profit (Weng [46]). Coordination strategies involve mechanization of a company's replenishment processes as well as the connection of buyer and supplier communities with real-time forecast, inventory on-hand, optimal lot sizing, quality improvements, inspections, and shipment information to reduce inventory and eliminate unnecessary expenses. The so-called integrated supply chain models simulate today's business practices (e.g., automotive, apparel, grocery) where there exists a long relationship between buyers and suppliers.

Keywords. Integrated model, lead time reduction, controllable backorder, trade-credit financing, distribution-free approach.

1 Department of Mathematics, Jadavpur University, Jadavpur, Kolkata 700032, India.

*Corresponding author: ss. sumonsarkar@gmail.com 
In many cases it is very important to control the lead time to manage the supply chain efficiently. Typically, lead time consists of order preparation, order transit, delivery time, and set-up time. Consideration of zero or constant lead time may result in deviation of the optimal solution from the actual one. Therefore, to make the supply chain more efficient, it is important to consider variable lead time. Generally, lead time is comprised of several components, and these components can be reduced by additional crashing costs. Reducing lead time may appear to be convenient in competitive situations because it can lower the safety stock level, reduce the stock-out losses, and improve the service level to the customer so as to increase the competitive edge in business.

Stochastic inventory models should not neglect backorder-lost sale mixture. In fact, it is reasonable to assume that only a fraction of the demand is backordered during the stock-out period, while the remaining fraction is lost. For example, customers whose needs are not serious can wait (these demands are backordered); while others cannot wait and meet their demands from other sources (these demands are lost). This phenomenon indicates that, longer the lead time is, higher the shortages are, the smaller the proportion of customers can wait, and hence smaller the backorder rate would be. Hence, the assumption of lead time (or waiting time) dependent backorder rate may reflect real life situations. Numerous inventory models have been developed to include this feature. However, in integrated SC model, this feature has been rarely considered.

In a business organization, the retailer usually pay the price of purchased quantity immediately. But if the retailer is given some delay time for payment, he/she may tend to buy more items. The retailer can earn interest from the revenue generated during the delay period. The use of the credit period can be seen in many deterministic inventory models. However, the use of credit period in stochastic inventory model is rarely found in the literature.

In some practical situations, information about the demand distribution may be rather limited. That is, decision makers only know an estimate of the mean and variance, but not the specific distribution types. In this scenario, the demand is generally considered to be a normally distributed random variable over a given period of time. However, the normal distribution does not provide the best protection against the occurrence of other distributions with the same mean and variance. Therefore, it is a challenge to the inventory/supply chain managers to make decisions without having idea of lead time demand distribution. That is, the replenishment policy can be optimized considering the worst non-negative distribution with the given mean and variance. This is called "minimax distribution-free approach". Due to its practicality (easy to use) and optimality (under certain conditions), it has received great attention in the inventory management literature. The reader is referred to some of the recent works dealing with distribution free approach, e.g. [5, 22, 23].

Many industries have dedicated efforts to improve customer service, control order frequency and reduce costs with their business partners. In this regard, the following questions may be raised from manager's view points:

I. What would be the optimal ordering policy for an industry if demand during replenishment lead time is stochastic?

II. What impact does lead time have on the backorder rate?

III. In which condition an industry manager should invest money to reduce lead time?

IV. What steps a manager will adopt when lead time demand distribution is unknown?

In an attempt to find out the answers to the above questions, this paper presents a continuous review integrated single-manufacturer single-retailer supply chain model with stochastic demand under controllable lead time. The manufacturer delivers the retailer's order quantity in a number of equal-sized shipments. Shortages are allowed in the retailer's inventory and a fraction of shortages are partially backlogged with lead time dependent backlogging rate. Initially the model is developed for the case when lead time demand distribution is known (normal distribution) and thereafter, the model is developed for unknown distribution case. Distribution-free approach is employed to find the optimal solution when lead time demand distribution is unknown. In this study, we assume that the long-term strategic partnership between the retailer and the manufacturer is well established and, therefore, the retailer and the manufacturer cooperate and share information with each other. Our goal is to find the optimal order quantity, safety factor, backorder rate, and the number of shipments by minimizing the annual total cost of the integrated system. Rest of the paper is organized as follows: Section 2 reviews 
the relevant literature. Notation and assumptions are given in Section 3. In Section 4, the proposed model is formulated mathematically. Section 5 describes the solution procedure of the model. Numerical examples are given in Section 6. Sensitivity analysis is presented in Section 7 and finally the paper is concluded in Section 8.

\section{Literature REVIEW}

In the retailing industry, WalMart, and Proctor and Gamble received substantial collaboration benefits by implementing collaborative planning and replenishment, a business model that intends to help supply chain members to collaborate in both tactical and strategic levels. Therefore, during the last few years, research on integrated manufacturer-retailer blue supply chain problem has been primarily focused on shipment schedule in terms of the size and frequency of shipments transferred between both parties. The cooperation between the upstream and downstream players gives a far greater benefit than a non-collaborative relationship. Goyal [13] was the first researcher who introduced a single-supplier single-buyer integrated inventory model. Banerjee [3] generalized Goyal's model and presented a joint economic lot size model where the vendor produces order on lot-for-lot basis to fulfill the buyer's order quantity under deterministic condition. Further, Goyal [15] relaxed the lot-for-lot policy of the vendor to generalize Banerjee's model. Later, Ha and Kim [16] generalized Goyal's [15] model and developed an integrated lot-splitting model facilitating multiple shipments in small lots.

In the literature, most of the supply chain models have been developed assuming lead time as a fixed or deterministic parameter. Although this assumption follows JIT (just-in-time) philosophy, it is not fitted in most of the modern complex setups where overseas, containerized, and air-freight shipping are involved. Liao and Shyu [29] were the first researchers to study lead time reduction in stochastic environment. In their model, they assumed that the lead time can be decomposed into several components having different crashing costs for reducing to a specified minimum duration. Thereafter, a number of researchers have contributed significantly in controllable lead time literature under various assumptions $[4,35,37,47]$.

Pan and Yang [40] were the first authors who studied lead time reduction in a setting with more than one economic actor. They considered a system where the product is delivered to a single buyer from a single vendor and assumed that the vendor may reduce lead time according to the scheme proposed by Liao and Shyu [29]. Ouyang et al. [38] extended Pan and Yang's [40] model by considering shortages and taking reorder point as a decision variable. Further, they solved the model using minimax distribution-free approach where only the first and second moments of the probability of lead time demand were known and finite. They obtained total cost lower than Pan and Yang's [40] model. Further extensions can be found in Giri and Roy [11], Jha and Shanker [20], Mandal and Giri [31] who studied the effects of lead time reduction in single-vendor multi-buyer supply chain system; Yang and Pan [49], Wu et al. [48], Ouyang et al. [39], Sarkar and Giri [41], who included quality considerations in the model formulation; Jha and Shanker [19], Y. Li et al. [27], and G. Li et al. [28] who considered service level constraint with lead time reduction.

Heydari et al. [17] used lead time reduction as an incentive mechanism in order to convince the buyer to participate in the coordination plan. The showed that a smaller lead time is beneficial to the buyer because of a lower inventory cost. Yang et al. [50] developed a newsvendor model to investigate inventory competition in a dual-channel supply chain and explored the delivery lead time decision in the direct channel. Zikopoulos [51] studied a remanufacturing system and examined the advisability taking into account the stochastic remanufacturing lead-time under different scenarios of returns' quality and demand for remanufactured products. Recently, Sarkar and Giri [42] considered the case where the replenishment lead time is a function of lot size and transportation time, and determined the optimal lot size which minimizes the total cost of the supply chain.

Due to variable lead time, sometimes the vendor may fail to deliver a lot within the desired lead time. As a result, the buyer may faces stock-out situation, in which case, customers' demand is not fulfilled resulting a financial loss. Moreover, the unsatisfied customers may not turn up next time to meet their demand from the same source. This indicates that, in reality the backorder rate should not be constant. Ouyang et al. [37] generalized Ben-Daya and Raouf's [4] model by considering mixture of backorder and lost sales. Ouyang and Chuang [36] considered backorder rate as a control variable to generalize Ouyang et al.'s [37] model. 
TABLE 1. A comparison of the present model with some related works in the literature.

\begin{tabular}{|c|c|c|c|c|c|c|}
\hline Author(s) & $\begin{array}{l}\text { Integrated } \\
\text { model }\end{array}$ & $\begin{array}{c}\text { Controllable } \\
\text { lead time }\end{array}$ & $\begin{array}{c}\text { Variable } \\
\text { backorder } \\
\text { rate }\end{array}$ & $\begin{array}{c}\text { Trade } \\
\text { credit } \\
\text { financing }\end{array}$ & $\begin{array}{l}\text { Variable } \\
\text { safety } \\
\text { factor }\end{array}$ & $\begin{array}{c}\text { Distribution } \\
\text { free } \\
\text { approach }\end{array}$ \\
\hline \multicolumn{7}{|l|}{ Kumar and Goswami [22] } \\
\hline Liao and Shyu [29] & & $\sqrt{ }$ & & & & \\
\hline Ouyang et al. [37] & & $\sqrt{ }$ & & & & \\
\hline Pan and Yang [40] & $\sqrt{ }$ & $\sqrt{ }$ & & & & \\
\hline Ouyang et al. [38] & $\sqrt{ }$ & $\sqrt{ }$ & & & $\sqrt{ }$ & $\sqrt{ }$ \\
\hline Yang and Pan [49] & $\sqrt{ }$ & $\sqrt{ }$ & & & & \\
\hline Ouyang et al. [39] & $\sqrt{ }$ & $\sqrt{ }$ & & & & \\
\hline Ouyang and Chuang [36] & & $\sqrt{ }$ & $\sqrt{ }$ & & & $\sqrt{ }$ \\
\hline Sarkar et al. [44] & & $\sqrt{ }$ & & & $\sqrt{ }$ & $\sqrt{ }$ \\
\hline Sarkar and Giri [42] & $\sqrt{ }$ & $\sqrt{ }$ & & & $\sqrt{ }$ & \\
\hline Ouyang and Chuang [36] & & $\sqrt{ }$ & $\sqrt{ }$ & & & $\sqrt{ }$ \\
\hline Lee $[25]$ & & $\sqrt{ }$ & $\sqrt{ }$ & & & $\sqrt{ }$ \\
\hline Lee et al. $[26]$ & & $\sqrt{ }$ & $\sqrt{ }$ & & & $\sqrt{ }$ \\
\hline Chung and Huang [8] & & & & $\sqrt{ }$ & & \\
\hline Chen and Kang [7] & $\sqrt{ }$ & & & $\sqrt{ }$ & & \\
\hline Huang [18] & $\sqrt{ }$ & $\sqrt{ }$ & & $\sqrt{ }$ & & \\
\hline Wu et al. [48] & $\sqrt{ }$ & $\sqrt{ }$ & & & $\sqrt{ }$ & $\sqrt{ }$ \\
\hline This paper & $\sqrt{ }$ & $\sqrt{ }$ & $\sqrt{ }$ & $\sqrt{ }$ & $\sqrt{ }$ & $\sqrt{ }$ \\
\hline
\end{tabular}

Lee [25] and Lee et al. [26] analyzed two inventory models with mixture of normally distributed lead time demand and controllable negative exponential backorder rate. Sarkar et al. [44] studied an inventory model with quality improvement and backorder price discount under controllable lead time. Mishra and Tripathy [33] developed an inventory model with time dependent Weibull deterioration and salvage value. Further, Mishra [32] proposed an inventory model to develop an optimal pricing policy for deteriorating items with stock and price dependent demand under partially backlogged shortages. Braglia et al. [5] studied a periodic-review joint-replenishment problem (JRP) with stochastic demands, backorder-lost sale mixture, and controllable major ordering cost and lead times. Braglia et al. [6] proposed a continuous review $(Q, r)$ inventory model for deteriorating item with random demand and partial backlogging.

In today's competitive business world, organizations are using various types of promotional tool in order to increase their sales volumes. One such tool is trade-credit or permissible delay-in-payments where the retailer need not to pay for the goods purchased until a prescribed period offered by the vendor. During the delay period, the retailer can earn interest from bank/share market by using the revenue on sales. To address the issue of trade-credit, researchers have made a great deal of efforts $[1,14,24,30]$. Chung and Huang [8] proposed a two-warehouse deteriorating inventory model with limited storage capacity under permissible delay in payments. Chen and Kang [7] developed an integrated vendor-buyer model with variant permissible delay in payments and imperfect quality item. Huang [18] developed an integrated inventory model to determine the optimal policy under conditions of order processing cost reduction and permissible delay in payments. Mishra et al. [34] developed an optimal ordering and pricing policy for perishable items under conditions of permissible delays. Tiwari et al. [45] investigated an inventory model for deteriorating items with unreliable supply and trade credit policy. Wu et al. [48] dealt with a probabilistic continuous review $(Q, r)$ inventory policy under permissible delay in payments where the supplier offers a credit period that is less than average duration of the inventory cycle. Arkan and Hejazi [2] designed a supply chain model for the coordination between a single buyer and a single supplier considering credit period and controllable lead time. 
A comparison of the present model with closely related models available in the existing literature is given in Table 1. It is seen from the literature review that the integrated supply chain models dealing with controllable lead time and stochastic demand are formulated based on the assumption of full backorder or fixed partial backorder. However, when an item is on backorder, a customer may look elsewhere for a substitute product, especially if the expected wait time until the product becomes available is long. That is, a longer lead time increases the shortage amount as well as decreases the backorder rate. The present work is close to the work of Ouyang et al. [38]. However, Ouyang et al.'s [38] model has a few distinct differences with the study at hand. First of all, their model assumes that shortages are fully backlogged, while in this study, we investigate the case where shortages are partially backlogged with backorder rate as a function of lead time through shortages quantity. In addition, we found that, trade credit inventory problem has been studied for many times in the literatures under deterministic as well as periodic review inventory system with less attention being given to probabilistic and continuous review inventory system. This paper therefore contributes to the literature by proposing a continuous review integrated supply chain model with stochastic demand under variable backorder rate and trade credit financing.

\section{Notation AND ASSUMPtions}

We use the following notation to develop the proposed model.

\begin{tabular}{|c|c|}
\hline & Description \\
\hline \multicolumn{2}{|c|}{ Decision variables } \\
\hline$Q$ & Retailer's ordered quantity (units) \\
\hline$L$ & Retailer's lead time (week) \\
\hline$k$ & Safety factor \\
\hline$\beta$ & $\begin{array}{l}\text { Fraction of demand which is backordered during stock-out } \\
\text { period, } \beta \in[0,1]\end{array}$ \\
\hline$m$ & Number of deliveries from the manufacturer to the retailer \\
\hline \multicolumn{2}{|r|}{ 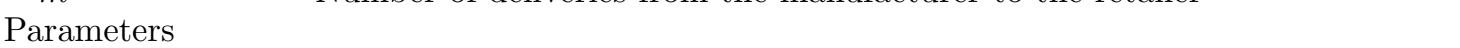 } \\
\hline$D$ & Annual demand at the retailer (units/year) \\
\hline$S$ & Manufacturer's setup cost per setup (\$/setup) \\
\hline$A$ & Retailer's ordering cost per order $(\$ /$ order $)$ \\
\hline$r_{b}$ & Retailer's holding cost rate per unit per unit time \\
\hline$r_{v}$ & Manufacturer's holding cost rate per unit time \\
\hline$\pi_{0}$ & Retailer's marginal profit (\$/unit) \\
\hline$\pi$ & Unit shortage cost at the retailer (\$/unit) \\
\hline$C(L)$ & Lead time crashing cost function \\
\hline$r$ & Reorder point at the retailer \\
\hline$t_{c}$ & Retailer's trade-credit period (year) \\
\hline$c_{b}$ & Purchasing price $(\$ /$ item $)$ \\
\hline$c_{s}$ & Selling price $(\$ /$ item $)$ \\
\hline$c_{v}$ & Unit production cost at the manufacturer $(\$ /$ item $)$ \\
\hline$I_{c}$ & $\begin{array}{l}\text { Fixed interest rate at which the retailer has to pay to the bank } \\
\text { for the remaining amount of stock during the period } \\
t_{c} \text { to } Q / D(\$ / \text { year })\end{array}$ \\
\hline$I_{d}$ & Fixed interest rate for the revenue earned by the retailer $(\$ / \$ /$ year $)$ \\
\hline$I_{v}$ & $\begin{array}{l}\text { Fixed interest rate for calculating the manufacturer's interest (opportunity) } \\
\text { loss due to trade-credit offer ( } \$ / \text { year) }\end{array}$ \\
\hline$\sigma$ & Standard deviation of the lead time demand \\
\hline$u_{i}$ & $\begin{array}{l}i \text { th component of lead time with } u_{i} \text { as minimum duration (days), } \\
i=1,2, \ldots, n\end{array}$ \\
\hline
\end{tabular}




\begin{tabular}{ll}
\hline \multicolumn{1}{c}{ Description } \\
\hline$v_{i}$ & $\begin{array}{l}i \text { th component of lead time with } v_{i} \text { as normal duration (days), } \\
i=1,2, \ldots, n\end{array}$ \\
$m_{i}$ & $\begin{array}{l}i \text { th component of lead time with } m_{i} \text { as crashing cost per day, } \\
i=1,2,3, \ldots n\end{array}$ \\
$X$ & $\begin{array}{l}\text { Lead time demand having distribution function } F, \text { finite mean } D L \text { and } \\
\text { standard deviation } \sigma \sqrt{L}\end{array}$ \\
$E(X)$ & Mathematical expectation of $X$ \\
$x^{+}$ & max $\{x, 0\}$ \\
$\Omega$ & Class of p.d.f.s with finite mean $D L$ and standard deviation $\sigma \sqrt{L}$ \\
$E(X-r)^{+}$ & Expected shortage quantity at the end of the cycle \\
ETC $_{b}$ & Expected average cost for the retailer \\
ETC $_{v}$ & Average cost for the manufacturer \\
ETC $^{N}$ & Expected average cost of the integrated system in normal distribution case \\
ETC $^{W}$ & Expected average cost of the integrated system in distribution-free case
\end{tabular}

We make the following assumptions to develop the model:

1. A supply chain consisting a single-manufacturer and a single-retailer deals with a single type of item.

2. The retailer places an order of size $m Q$ which the manufacturer produces with a finite production rate $P(>D)$ in a single setup but ships the entire quantity to the retailer over $m$ deliveries of equal size.

3. The retailer's inventory is continuously monitored. Replenishment is planed whenever the inventory level drops to the reorder point $r$. The reorder point $r$ is defined by $r=$ the expected demand during lead time $(D L)+$ safety stock $(k) \times$ standard deviation

of lead time demand $(\sigma \sqrt{L})$, i.e., $r=D L+k \sigma \sqrt{L}$, where $k$ is the safety factor and satisfies $\operatorname{Pr}(X>r)=q$ where $q$ represents the allowable stock-out probability during lead time (see Tiwari et al. [45], Sarkar et al. [43]).

4. The lead time $L$ consists of $n$ mutually independent components. The $i$ th component has a minimum duration $u_{i}$ days, normal duration $v_{i}$ days, and a crashing cost $m_{i}$ per day. Further, we rearrange $m_{i}$ as $m_{1} \leq m_{2} \leq m_{3}, \ldots, \leq m_{n}$. Then, it is clear that the reduction of lead time should first occur in component 1 (because it has the minimum unit crashing cost), and then component 2 , and so on.

5. Let $L_{0}=\sum_{j=1}^{n} v_{j}$ denote the maximum duration of lead time and $L_{i}$ as the length of lead time with components $1,2, \ldots, i$ crashed to their minimum durations. Then $L_{i}$ can be expressed as (see Liao and Shyu [29])

$$
L_{i}=\sum_{j=1}^{n} v_{j}-\sum_{j=1}^{i}\left(v_{j}-u_{j}\right)
$$

where $i=1,2,3, \ldots, n$, and the lead time crashing cost function $C(L)$ as

$$
C(L)=m_{i}\left(L_{i-1}-L\right)+\sum_{j=1}^{i-1} m_{j}\left(v_{j}-u_{j}\right) .
$$

6. If a shortened lead time is requested then the extra costs incurred by the manufacturer will be fully transferred to the retailer. Therefore, lead time crash cost is the retailer's cost component.

7. The manufacturer offers a certain trade credit period $t_{c}$ to attract the retailer to cooperate in the integrated strategy. Therefore, the retailer need not to pay immediately after receiving the deliveries. The offered credit period $t_{c}$ is less than the reorder interval, which means that the credit period cannot be longer than the time at which another order is placed. This is in agreement with the usual practice.

8. The retailer deposits the sale income in a bank with annual interest rate $I_{d}$ before the payment is due. At the payment time, the distributor pays off the purchased products' cost for all products to the manufacturer. 
The retailer has a loan from a bank for the unsold products' cost. During the period of delayed payment, the manufacturer has an interest (opportunity) loss for all products with annual rate $I_{v}$ where $I_{v}=I_{d}$.

9. The backorder rate is variable and it is a function of lead time.

\section{Mathematical MODEL}

As mentioned in assumption (3), whenever the inventory level drops to the reorder point $r$, the retailer requests the manufacturer for a delivery. The manufacturer produces $m Q$ units (where $m$ is an integer) at one setup. Therefore, the average cycle time for the manufacturer is $\frac{m Q}{D}$ and the average length of a replenishment cycle is $\frac{Q}{D}$.

According to our assumption, the lead time demand $X$ has a probability density function $f(x)$ with mean $D L$ and standard deviation $\sigma \sqrt{L}$ and the reorder point $r=D+k \sigma \sqrt{L}$. Shortages occur when $X>r$. The retailer's expected shortage quantity at the end of a replenishment cycle is $E(X-r)^{+}$and hence, the expected backorder quantity is $\beta E(X-r)^{+}$. Therefore, the expected loss in sales per shipment cycle is $(1-\beta) E(X-r)^{+}$ and the expected stock-out cost per replenishment cycle is $\left[\pi+\pi_{0}(1-\beta)\right] E(X-r)^{+}$.

Further, at the beginning of each replenishment cycle, the retailer's expected net inventory is the safety stock $(r-D L)$ plus the previous replenishment cycle's lost sales $(1-\beta) E(X-r)^{+}$. The expected net inventory level immediately after a replenishment is $Q+r-D L+(1-\beta) E(X-r)^{+}$. Therefore, the average inventory over a replenishment cycle is $\frac{Q}{2}+r-D L+(1-\beta) E(X-r)^{+}$. Hence, the retailer's holding cost per unit time is $h_{b}\left[\frac{Q}{2}+r-D L+(1-\beta) E(X-r)^{+}\right]$. Further, the safety stock plus the previous replenishment cycle's lost sales is $r-D L+(1-\beta) E(X-r)^{+}$which is carried throughout the replenishment cycle. Therefore, the total interest charged at a rate $I_{c}$ by the manufacturer to the retailer for this amount of stock is $c_{b} I_{c}\left[r-D L+(1-\beta) E(X-r)^{+}\right]$.

We assume that the permissible delay period is $t_{c}$ which is less than the reorder interval. This assumption is realistic, as the payment for the earlier order should be cleared before another order is placed. Here, the retailer earns interest on the sales revenue at the rate $I_{d}$ during the time period $\left(0, t_{c}\right)$. Therefore, the retailer's interest earn per unit time is $\frac{c_{s} I_{d} D}{Q} \int_{0}^{t_{c}} D t \mathrm{~d} t=\frac{D^{2} t_{c}^{2} c_{s} I_{d}}{2 Q}$. Additionally, the previous replenishment cycle's backlogged items are cleared at the beginning of the cycle. Therefore, the interest earned per unit time from the backlogged items is $\frac{c_{s} I_{d} t_{c} D}{Q} \beta E(X-r)^{+}$. The retailer still has some inventory $\left(Q-D t_{c}\right)$ after the credit period $t_{c}$. If he takes a short term loan from the bank at an interest rate $I_{c}$ for the duration $\left(t_{c}, \frac{Q}{D}\right)$ to finance the unsold stock then his opportunity cost (due to payment of interest) per unit time is $\frac{c_{b} I_{c} D}{Q} \int_{t_{c}}^{Q / D}(Q-D t) \mathrm{d} t=\frac{\left(Q-D t_{c}\right)^{2} c_{b} I_{c}}{2 Q}$.

Though in most of the existing literature the backorder rate is considered as constant, in this paper, we take the backorder rate $\beta$ as a variable and define it as

$$
\beta=\frac{1}{1+\alpha E(X-r)^{+}},
$$

$\alpha(0<\alpha<\infty)$ being a constant. From (4.1), we see that the backorder rate is a decreasing function of shortage quantity. Further, as $\alpha \rightarrow \infty$, we have $\beta \rightarrow 0$ (complete lostsale case) and as $\alpha \rightarrow 0$, we have $\beta \rightarrow 1$ (complete backordered case).

The retailer's expected total cost per unit time is

$$
\begin{aligned}
\operatorname{ETC}_{b}(Q, r, L)= & \text { Ordering cost }+ \text { Holding cost }+ \text { Safety stock plus previous cycle's lostsale } \\
& \text { cost }+ \text { Stockout cost }+ \text { Opportunity (interest) cost }- \text { Interest earned } \\
= & \frac{A D}{Q}+\frac{r_{b} c_{b} Q}{2}+c_{b}\left(r_{b}+I_{c}\right)\left[r-D L+(1-\beta) E(X-r)^{+}\right] \\
& +\frac{D}{Q}\left[\pi+\pi_{0}(1-\beta)\right] E(X-r)^{+}+\frac{\left(Q-D t_{c}\right)^{2} c_{b} I_{c}}{2 Q} \\
& -\frac{D^{2} t_{c}^{2} c_{s} I_{d}}{2 Q}-\frac{c_{s} t_{c} I_{d} D \beta}{Q} E(X-r)^{+}
\end{aligned}
$$




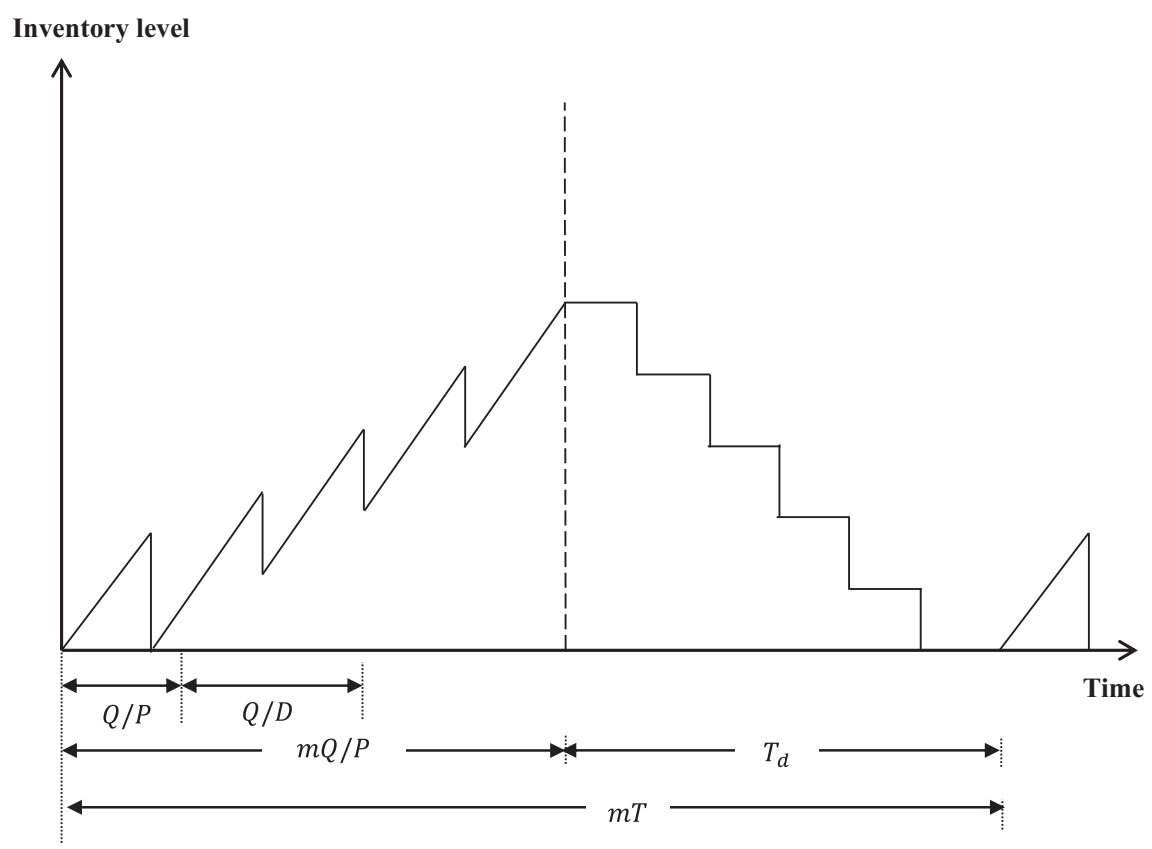

FiguRE 1. Manufacturer's inventory level in a cycle with time.

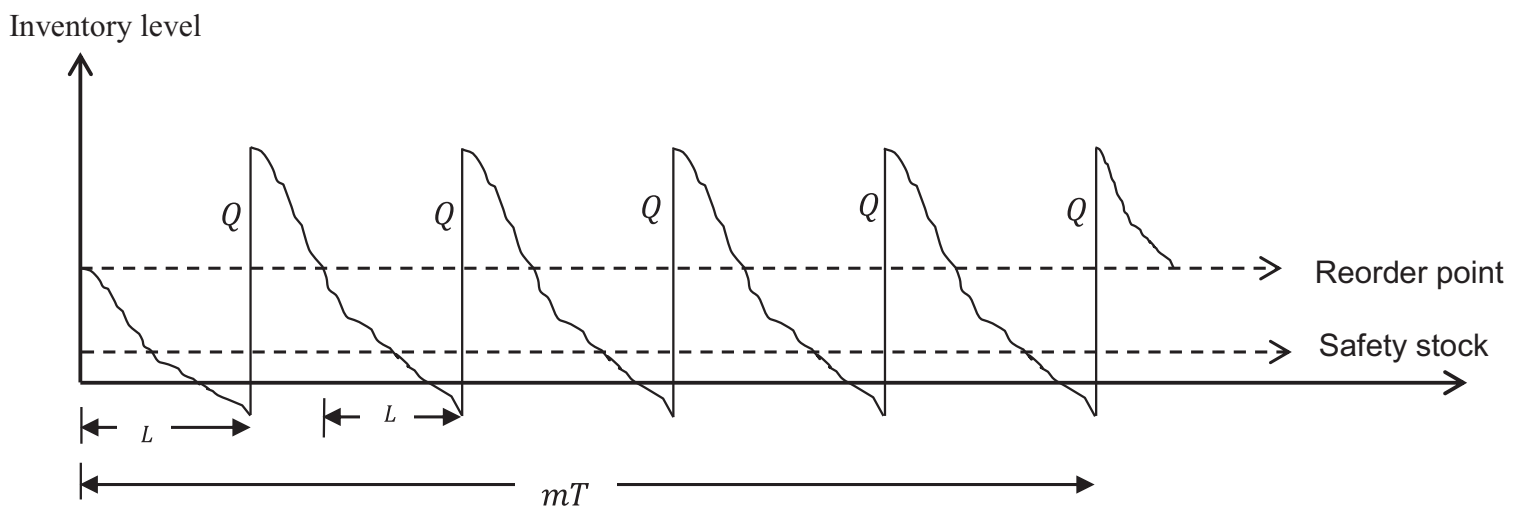

FIGURE 2. Retailer's inventory in manufacturer's one cycle.

On the other hand, the manufacturer's total cost is

$$
T C_{v}(m)=\text { Setup cost }+ \text { Holding cost }+ \text { Opportunity (interest) cost. }
$$

Figure 1 displays the inventory pattern of the manufacturer. The manufacturer delivers the first lot as soon as it has $Q$ items and then starts building up the inventory as its production rate is higher than that of the demand. This build-up of inventory in the production time $\left(T_{p}\right)$ is supplied in equal shipments during the non-production time $\left(T_{d}\right)$. Figure 2 depicts the behavior of the retailer's inventory. Figure 3 shows the same behavior of inventory in another form. The triangle "ABG" and the rectangle "BCGE" are the total inventory 


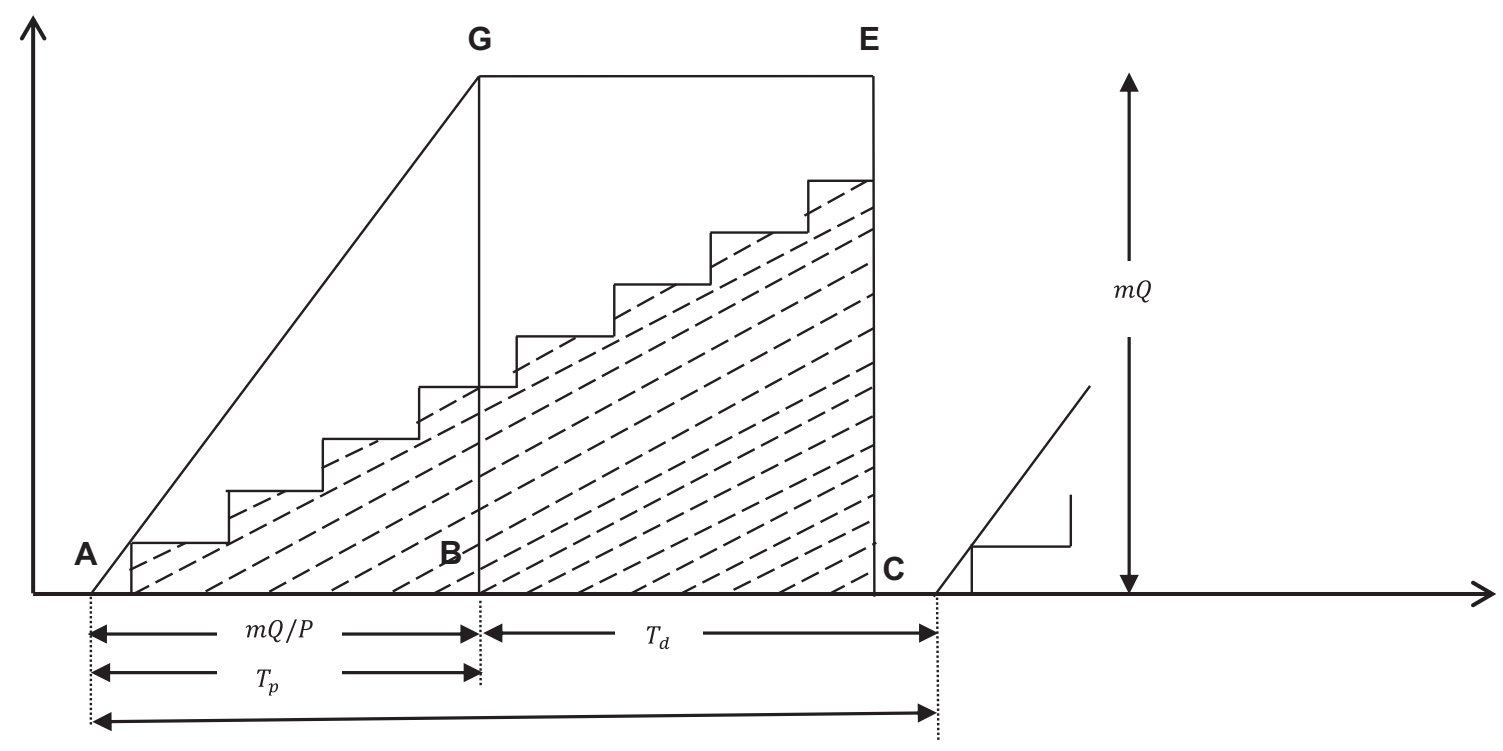

FiguRE 3. Time-weighted inventory for manufacturer and retailer.

at the manufacturer's end while the shaded rectangles are the total inventory supplied to the retailer. Hence, the total inventory or stock level at the manufacturer can be determined by using Figure 3.

Following the method in Goyal [13], the total inventory at the manufacturer in a cycle is the sum of areas of the triangle AGB and the rectangle BGCE in Figure 3, i.e.,

$$
\begin{aligned}
\text { Area }_{\mathrm{ABG}} & =\frac{1}{2}(m Q / P) m Q=\frac{m^{2} Q^{2}}{2 P}, \\
\text { Area }_{\mathrm{BCGE}} & =m Q\left[(m-1)\left(\frac{Q}{D}-\frac{Q}{P}\right)\right]=\frac{m Q^{2}(m-1)(P-D)}{P D} .
\end{aligned}
$$

The total inventory moved to the retailer in a cycle by the manufacturer is $m(m-1) Q^{2} / 2 D$. So, the manufacturer's total inventory in a cycle is

$$
\begin{aligned}
& =\frac{m^{2} Q^{2}}{2 P}+\frac{m Q^{2}(m-1)(P-D)}{P D}-\frac{m(m-1) Q^{2}}{2 D}, \\
& =\frac{m Q^{2}}{2 D}\left\{(m-1)-(m-2) \frac{D}{P}\right\} .
\end{aligned}
$$

Therefore, the manufacturer's holding cost per unit time is

$$
=\frac{r_{v} c_{v} Q}{2}\left[(m-1)-(m-2) \frac{D}{P}\right] .
$$

The manufacturer's setup cost per unit time is $\frac{S D}{m Q}$.

Hence, the manufacturer's total cost per unit time is

$$
T C_{v}(m)=\frac{S D}{m Q}+\frac{r_{v} c_{v} Q}{2}\left\{(m-1)-(m-2) \frac{D}{P}\right\}+I_{v} c_{b} t_{c} D .
$$


Therefore, the expected average total cost of the supply chain is the sum of the retailer's expected average total cost given by (4.2) and manufacturer's average total cost given by (4.3), i.e.,

$$
\begin{aligned}
\operatorname{ETC}(Q, r, L, m)= & \frac{D}{Q}\left[A+C(L)+\frac{S}{m}\right]+\frac{r_{b} c_{b} Q}{2}+c_{b}\left(r_{b}+I_{c}\right)\left[r-D L+(1-\beta) E(X-r)^{+}\right] \\
& +\frac{D}{Q}\left[\pi+\pi_{0}(1-\beta)\right] E(X-r)^{+}+\frac{\left(Q-D t_{c}\right)^{2} c_{b} I_{c}}{2 Q}-\frac{D^{2} t_{c}^{2} c_{s} I_{d}}{2 Q} \\
& -\frac{D c_{s} t_{c} I_{d}}{Q} \beta E(X-r)^{+}+\frac{r_{v} c_{v} Q}{2}\left\{(m-1)-(m-2) \frac{D}{P}\right\}+I_{v} c_{b} t_{c} D .
\end{aligned}
$$

\section{Solution PRocedure}

\subsection{Lead time demand follows normal distribution}

In this sub-section, we assume that the lead time demand $X$ is normally distributed with mean $D L$ and standard deviation $\sigma \sqrt{L}$. We note that $r=D L+k \sigma \sqrt{L}$ and the expected shortage quantity at the end of a cycle is

$$
\begin{aligned}
E(X-r)^{+} & =\int_{r}^{\infty}(x-r) f(x) \mathrm{d} x \\
& =\int_{D L+k \sigma \sqrt{L}}^{\infty}\{x-(D L+k \sigma \sqrt{L})\} \frac{1}{\sigma \sqrt{L} \sqrt{2 \pi}} e^{-\frac{(x-D L)^{2}}{2 \sigma^{2} L}} \mathrm{~d} x
\end{aligned}
$$

After some calculations, the above expression reduces to (see Pan and Yang [40]; Ouyang et al. [38]; Sarkar et al. [44])

$$
E(X-r)^{+}=\sigma \sqrt{L} \Psi(k),
$$

where $\Psi(k)=\phi(k)-k[1-\Phi(k)]$, and $\phi$ and $\Phi$ denote the standard normal probability density function and distribution function, respectively.

Substituting the value of $E(X-r)^{+}$in (1), we get

$$
\beta=\frac{1}{1+\alpha \sigma \sqrt{L} \Psi(k)} .
$$

Therefore, when lead time demand follows normal distribution, the expected average total cost of the supply chain can be obtained by using (5.1) and (5.2) in (4.4) as

$$
\begin{aligned}
\operatorname{ETC}^{N}(Q, k, L, m)= & \frac{D}{Q}[G(m)+C(L)]+c_{b}\left(r_{b}+I_{c}\right) k \sigma \sqrt{L}+\frac{Q}{2} H(m) \\
& +\left\{\frac{D}{Q}\left(\pi-\frac{c_{s} t_{c} I_{d}}{1+\alpha \sigma \sqrt{L} \Psi(k)}\right)+\frac{\alpha \sigma \sqrt{L} \Psi(k) M(Q)}{1+\alpha \sigma \sqrt{L} \Psi(k)}\right\} \sigma \sqrt{L} \Psi(k) \\
& +\frac{\left(Q-D t_{c}\right)^{2} c_{b} I_{c}}{2 Q}-\frac{D^{2} t_{c}^{2} c_{s} I_{d}}{2 Q}+I_{v} c_{b} t_{c} D \\
\text { where } G(m)= & A+\frac{S}{m} \\
M(Q)= & \frac{D \pi_{0}}{Q}+c_{b}\left(r_{b}+I_{c}\right) \\
H(m)= & r_{b} c_{b}+r_{v} c_{v}\left[(m-1)-(m-2) \frac{D}{P}\right]
\end{aligned}
$$


Note 1. It is clear that if $I_{d}=0, I_{c}=0, I_{v}=0$ and $\alpha=0$, i.e., the case when trade-credit is not allowed and shortages are fully backlogged, (5.3) reducers to

$$
\operatorname{ETC}^{N}(Q, k, L, m)=\frac{D}{Q}[G(m)+\pi \sigma \sqrt{L} \Psi(k)+C(L)]+\frac{Q}{2} H(m)+r_{b} c_{b} k \sigma \sqrt{L}
$$

which is exactly same as Equation (7) of Ouyang et al.'s [38]. Therefore, Ouyang et al.'s [38] model is a special case of our model.

Note 2. If we take $I_{d}=0$ and $I_{c}=0$ then the retailer's cost function (4.2) becomes

$$
\begin{aligned}
\operatorname{ETC}_{b}(Q, L)= & \frac{D}{Q}[A+R(L)]+r_{b} c_{b}\left(\frac{Q}{2}+k \sigma \sqrt{L}\right) \\
& +\left\{\frac{r_{b} c_{b} \alpha \sigma \sqrt{L} \Psi(k)}{1+\alpha \sigma \sqrt{L} \Psi(k)}+\frac{D}{Q}\left[\pi+\frac{\pi_{0} \alpha \sigma \sqrt{L} \Psi(k)}{1+\alpha \sigma \sqrt{L} \Psi(k)}\right]\right\} \sigma \sqrt{L} \Psi(k)
\end{aligned}
$$

which is same as the expected average cost derived by Ouyang and Chuang [36] (taking $r_{b} c_{b}=h, \Psi(k)=G(k)$, and $C(L)=R(L)$ ). This indicates that Ouyang and Chuang's [36] model is also a special case of our model.

In order to show that the expected cost function (5.3) is strictly convex i.e., it has a unique minimum, we derive the following propositions:

Proposition 5.1. For given values of $Q, k$, and $m, \operatorname{ETC}^{N}(Q, k, L, m)$ is concave in $L \in\left[L_{i}, L_{i-1}^{\prime}\right]$, where $L_{i-1}^{\prime}=\min \left\{L_{i-1},\left(\frac{\sqrt{\pi c_{s} t_{c} I_{d}}-\pi}{\pi \alpha \sigma \Psi(k)}\right)^{2}\right\}$.

Proof. See Appendix A. Hence, the minimum value of the expected total cost $\operatorname{ETC}^{N}(Q, k, L, m)$ will occur at the end points of the interval $\left[L_{i}, L_{i-1}^{\prime}\right]$ (see Liao and Shyu [29] and Ouyang et al. [38]).

Proposition 5.2. If $I_{c}>\frac{c_{s} I_{d}}{c_{b}}$, then for fixed values of $m$ and $L \in\left[L_{i}, L_{i-1}\right], \operatorname{ETC}^{N}(Q, k, L, m)$ is convex in $Q$ and $k$ for all $Q>0$ and $k>0$ such that $\Psi(k)>\frac{c_{s} t_{c} I_{d}}{\pi_{0} \alpha \sigma \sqrt{L}}$.

Proof. See Appendix B.

Proposition 5.3. For given values of $m$ and $L \in\left[L_{i}, L_{i-1}\right], E T C^{N}(Q, k, L, m)$ has a unique minimum provided that $I_{c}>\frac{c_{s} I_{d}}{c_{b}}$ and $k>0$ such that $\Psi(k)>\frac{c_{s} t_{c} I_{d}}{\pi_{0} \alpha \sigma \sqrt{L}}$, and the corresponding values of $Q$ and $k$ are given by

$$
\begin{aligned}
Q & =\sqrt{\frac{2 D[G(m)+\sigma \sqrt{L} \Psi(k) \Delta(k, L)+C(L)]+F_{1}}{F_{2}+H(m)}}, \\
k & =\Phi^{-1}\left(1-\frac{F_{2}[V(k, L)]^{2} Q}{v(k, L) Q M(Q)[1+V(k, L)]+D \pi[V(k, L)]^{2}-D s t_{c} I_{d}}\right) .
\end{aligned}
$$

Proof. See Appendix C.

The optimal value of $m$ i.e. $m^{*}$ can be obtained from

$$
\operatorname{ETC}^{N}\left(m^{*}-1\right) \geq \operatorname{ETC}^{N}\left(m^{*}\right) \leq \operatorname{ETC}^{N}\left(m^{*}+1\right)
$$

The following algorithm is suggested to obtain numerically the optimal values of $Q$ and $k$ for specific values of $m$ and $L$. 


\section{Algorithm 1.}

Step 1 Set $m=1$.

Step 2 For each $L_{i}, i=0,1,2, \ldots, n$, perform 2a to 2 c.

2a Set $k_{i 1}=0$ (implies $\left.\Psi\left(k_{i 1}\right)=0.39894\right)$.

2b Substituting $\Psi\left(k_{i 1}\right)$ into (10), evaluate $Q_{i 1}$.

2c Utilize $Q_{i 1}$ to obtain the value of $k_{i 2}$ from (11) by checking the normal table, and evaluate $\Psi\left(k_{i 2}\right)$.

$\mathbf{2 d}$ Repeat $2 \mathrm{~b}$ to $2 \mathrm{c}$ until no change occurs in the values of $Q_{i}$ and $k_{i}$.

Step 3 For each set of values $\left(Q_{i}, k_{i}, L_{i}, m\right)$, find $\operatorname{ETC}^{N}\left(Q_{i}, k_{i}, L_{i}, m\right), i=1,2, \ldots, n$.

Step 4 Find $\min _{i=0,1,2, \ldots, n} \operatorname{ETC}^{N}\left(Q_{i}, k_{i}, L_{i}, m\right)$.

If $\operatorname{ETC}^{N}\left(Q_{m}^{*}, k_{m}^{*}, L_{m}^{*}, m\right)=\min _{i=0,1,2, \ldots, n} \mathrm{ETC}^{N}\left(Q_{i}, k_{i}, L_{i}, m\right)$, then $\left(Q_{m}^{*}, k_{m}^{*}, L_{m}^{*}, m\right)$ is the optimal solution for fixed $m$.

Step 5 Set $m=m+1$ and repeat Steps 2,3 , and 4 to get $\operatorname{ETC}^{N}\left(Q_{m}^{*}, k_{m}^{*}, L_{m}^{*}, m\right)$.

Step 6 If $\operatorname{ETC}^{N}\left(Q_{m}^{*}, k_{m}^{*}, L_{m}^{*}, m\right) \leq \operatorname{ETC}^{N}\left(Q_{m-1}^{*}, k_{m-1}^{*}, L_{m-1}^{*}, m\right)$, then go to Step 5 ; otherwise, go to Step 7 .

Step 7 Set $\operatorname{ETC}^{N}\left(Q_{m}^{*}, k_{m}^{*}, L_{m}^{*}, m\right)=\operatorname{ETC}^{N}\left(Q_{m-1}^{*}, k_{m-1}^{*}, L_{m-1}^{*}, m\right)$. Then $\left(Q^{*}, k^{*}, L^{*}, m\right)$ is the optimal solution.

After substituting the values of $k^{*}$ and $L^{*}$, the optimal backorder rate and the reorder point can be obtained as

$$
\beta^{*}=\frac{1}{1+\alpha \sigma \sqrt{L^{*}} \Psi\left(k^{*}\right)} \text { and } r^{*}=D L^{*}+k^{*} \sigma \sqrt{L^{*}}
$$

\subsection{Lead time demand is distribution-free}

In many practical situations, the information about the probability distribution of the lead time demand is limited or unavailable. In this section, we relax the assumption of normally distributed lead time demand. We assume that the density function of the lead time demand belongs to $\Omega$ with finite mean $D L$ and standard deviation $\sigma \sqrt{L}$. If the distributional form of lead time demand $X$ is unknown, the exact value of $E(X-r)^{+}$ cannot be determined. Therefore, the min-max distribution-free approach is used to solve this problem (Gallego and Moon [9], Ouyang et al. [38], and Lee [25]):

$$
\min -\max _{F \in \Omega} \quad \operatorname{ETC}^{W}(Q, k, L, m) .
$$

The following proposition which was proposed by Gallego and Moon [9] is used to approximate the value of $E(X-r)^{+}$.

Proposition 5.4. For any $F \in \Omega$,

$$
E(X-r)^{+} \leq \frac{1}{2}\left\{\sqrt{\sigma^{2} L+(r-D L)^{2}-(r-D L)}\right\} .
$$

Substituting $r=D L+k \sigma \sqrt{L}$ in (5.10), the following inequality is obtained:

$$
E(X-r)^{+} \leq \frac{1}{2} \sigma \sqrt{L}\left(\sqrt{1+k^{2}}-k\right)
$$

Using the above inequality, the backorder rate $\beta$ can be expressed as

$$
\beta \geq \frac{1}{1+\frac{1}{2} \alpha \sigma \sqrt{L}\left(\sqrt{1+k^{2}}-k\right)} .
$$


Using (4.4) and (5.12), Equation (5.9) becomes

$$
\begin{aligned}
E T C^{W}(Q, L, k, m)= & \frac{D}{Q}[G(m)+C(L)]+c_{b}\left(r_{b}+I_{c}\right) k \sigma \sqrt{L}+\frac{r_{b} c_{b} Q}{2}+\frac{Q}{2} H(m) \\
& +\left[\left(\frac{\frac{1}{2} \alpha \sigma \sqrt{L}\left(\sqrt{1+k^{2}}-k\right)}{1+\frac{1}{2} \alpha \sigma \sqrt{L}\left(\sqrt{1+k^{2}}-k\right)}\right) M(Q)\right. \\
& \left.+\frac{D}{Q}\left(\pi-\frac{c_{s} t_{c} I_{d}}{1+\frac{1}{2} \alpha \sigma \sqrt{L}\left(\sqrt{1+k^{2}}-k\right)}\right)\right] \frac{1}{2} \sigma \sqrt{L}\left(\sqrt{1+k^{2}}-k\right) \\
& +\frac{\left(Q-D t_{c}\right)^{2} c_{b} I_{c}}{2 Q}-\frac{D^{2} t_{c}^{2} c_{s} I_{d}}{2 Q}+I_{v} c_{b} t_{c} D
\end{aligned}
$$

Similar to the case of normally distributed demand, it can be easily verified that, for fixed $(Q, k, m)$, $\operatorname{ETC}^{W}(Q, L, k, m)$ is convex in $L \in\left[L_{i}, L_{i-1}\right]$. Therefore, the minimum expected average cost will occur at the end point of the interval $\left[L_{i}, L_{i-1}\right]$. Further, keeping $m$ and $L \in\left[L_{i}, L_{i-1}\right]$ fixed, it can also be verified that $\operatorname{ETC}^{W}(Q, L, k, m)$ is convex in $Q$ and $k$. Therefore, for fixed values of $m$ and $L \in\left[L_{i}, L_{i-1}\right]$, the expected average cost will be minimum at the point $(Q, k)$ which satisfies $\partial \operatorname{ETC}^{W}(Q, L, k, m) / \partial Q=0$ and $\partial \operatorname{ETC}^{W}(Q, L, k, m) / \partial k=0$, simultaneously. This gives

$$
\begin{aligned}
Q & =\sqrt{\frac{2 D[G(m)+\sigma \sqrt{L} \Psi(k) \Upsilon(k, L)+C(L)]+F_{1}}{F_{2}+H(m)},} \\
{[1+\omega(k, L)]^{2} } & =\frac{\omega\left[Q M(Q)+D s I_{d} t_{c}\right]}{D \omega\left(\pi+\pi_{0}\right)-Q F_{2}(\omega+\alpha k \sigma \sqrt{L})},
\end{aligned}
$$

where $\omega(k, L)=\frac{1}{2} \alpha \sigma \sqrt{L}\left(\sqrt{1+k^{2}}-k\right), \quad \hat{\pi}=\pi+\frac{\pi_{0} \omega(k, L)}{1+\omega(k, L)} \quad$ and $\quad \Upsilon(k, L)=\hat{\pi}-\frac{c_{s} t_{c} I_{d}}{1+\omega(k, L)}$. The following algorithm is developed to obtain the optimal values of $Q$ and $k$ for a specific values of $m$ and $L \in\left[L_{i}, L_{i-1}\right]$.

\section{Algorithm 2.}

Step 1 Set $m=1$.

Step 2 For each $L_{i}, i=0,1,2, \ldots, n$, perform Steps $2 \mathrm{a}-2 \mathrm{c}$.

2a Set $k_{i 1}=0$.

2b Evaluate $Q_{i 1}$ from (5.14).

2c Utilize $Q_{i 1}$ to obtain the value of $k_{i 2}$ from (5.15).

2d Repeat Steps $2 \mathrm{~b}$ and 2c until no change occurs in the values of $Q_{i}$ and $k_{i}$.

Step 3 For each set of values $\left(Q_{i}, k_{i}, L_{i}, m\right)$, compute $\operatorname{ETC}^{W}\left(Q_{i}, k_{i}, L_{i}, m\right), i=1,2, \ldots, n$.

Step 4 Find $\min _{i=0,1,2, \ldots, n} \operatorname{ETC}^{W}\left(Q_{i}, k_{i}, L_{i}, m\right)$.

If $\operatorname{ETC}^{W}\left(Q_{m}^{* *}, k_{m}^{* *}, L_{m}^{* *}, m\right)=\min _{i=0,1,2, \ldots, n} \operatorname{ETC}^{W}\left(Q_{i}, k_{i}, L_{i}, m\right)$, then $\left(Q_{m}^{* *}, k_{m}^{* *}, L_{m}^{* *}, m\right)$ is the optimal solution for fixed $m$.

Step 5 Set $m=m+1$, repeat Steps $2-4$ to get $\operatorname{ETC}^{W}\left(Q_{m}^{* *}, k_{m}^{* *}, L_{m}^{* *}, m\right)$.

Step 6 If $\operatorname{ETC}^{W}\left(Q_{m}^{* *}, k_{m}^{* *}, L_{m}^{* *}, m\right) \leq \operatorname{ETC}^{W}\left(Q_{m-1}^{* *}, k_{m-1}^{* *}, L_{m-1}^{* *}, m\right)$, then go to Step 5 ; otherwise, go to Step 7 . Step $7 \operatorname{Set}_{\operatorname{ETC}}^{W}\left(Q_{m}^{* *}, k_{m}^{* *}, L_{m}^{* *}, m\right)=\operatorname{ETC}^{W}\left(Q_{m-1}^{* *}, k_{m-1}^{* *}, L_{m-1}^{* *}, m\right)$. Then $\left(Q^{* *}, k^{* *}, L^{* *}, m\right)$ is the optimal solution.

After substituting the values of $k^{* *}$ and $L^{* *}$, the optimal backorder rate and the reorder point can be obtained as

$$
\beta^{* *}=\frac{1}{1+\frac{1}{2} \alpha \sigma \sqrt{L^{* *}}\left(\sqrt{1+k^{* *^{2}}}-k^{* *}\right)} \text { and } r^{* *}=D L^{* *}+k^{* *} \sigma \sqrt{L^{* *}}
$$


TABle 2. Parameter values.

\begin{tabular}{llclcl}
\hline \hline Parameters & \multicolumn{1}{c}{ Values } & Parameters & \multicolumn{1}{c}{ Values } & Parameters & \multicolumn{1}{c}{ Values } \\
\hline$D$ & 600 units/year & $P$ & 2000 units & $S$ & $\$ 1500 /$ set up \\
$A$ & $\$ 200 /$ order & $r_{b}$ & $\$ 0.2 /$ unit/year & $r_{v}$ & $\$ 0.2 /$ unit/year \\
$c_{b}$ & $\$ 100 /$ unit/year & $c_{s}$ & $\$ 110 /$ unit/year & $c_{v}$ & $\$ 70 /$ unit/year \\
$\pi_{0}$ & $\$ 150 /$ unit & $\pi$ & $\$ 50 /$ unit & $\sigma$ & 7 units/week \\
\hline
\end{tabular}

TABLE 3. Lead time data.

\begin{tabular}{lccc}
\hline \hline $\begin{array}{l}\text { Lead time } \\
\text { component } i\end{array}$ & $\begin{array}{c}\text { Normal duration } \\
v_{i}(\text { days })\end{array}$ & $\begin{array}{c}\text { Minimum duration } \\
u_{i}(\text { days })\end{array}$ & $\begin{array}{c}\text { Unit crashing } \\
\text { cost } m_{i}(\$ / \text { day })\end{array}$ \\
\hline 1 & 20 & 6 & 0.4 \\
2 & 20 & 6 & 1.2 \\
3 & 16 & 9 & 5.0 \\
\hline
\end{tabular}

TABLE 4. Optimal results in Example 6.1.

\begin{tabular}{ccccccc}
\hline \hline$m$ & $L_{m}^{*}$ & $k_{m}^{*}$ & $R_{m}^{*}$ & $Q_{m}^{*}$ & $\beta_{m}^{*}$ & $\operatorname{ETC}^{N}\left(Q_{m}^{*}, k_{m}^{*}, L_{m}^{*}, m\right)$ \\
\hline 1 & 3 & 1.00 & 47 & 264 & 0.91 & $\$ 8349$ \\
2 & 4 & 1.20 & 63 & 174 & 0.93 & $\$ 7311$ \\
$\mathbf{3}$ & $\mathbf{4}$ & $\mathbf{1 . 3 1}$ & $\mathbf{6 4}$ & $\mathbf{1 3 6}$ & $\mathbf{0 . 9 4}$ & $\$ \mathbf{7 0 9 4}$ \\
4 & 4 & 1.39 & 66 & 114 & 0.95 & $\$ 7105$ \\
\hline
\end{tabular}

Notes. The bold values indicate the optimal solution of the decision variables.

\section{NumericAl EXAMPLES}

Example 6.1. In order to illustrate the solution procedure of the model, we consider in Table 2 the data which are used by Ouyang et al. [38]. For controllable backorder rate and trade-credit financing, we take some additional parameter-values as: $\pi_{0}=\$ 150 /$ unit, $\alpha=0.1, t_{c}=0.2$ years, $I_{d}=\$ 0.04 / \$ /$ year, $I_{c}=\$ 0.08 / \$ /$ year, $I_{v}=\$ 0.04 / \$ /$ year. The lead time has three components with data given in Table 3 . Using the lead time data and Algorithm 1, we obtain the results for the case when lead time demand follows normal distribution. The summary of optimal results is given in Table 4. Variation of the expected average cost with respect to number of shipments $m$ is depicted in Figure 4. From Table 4, we obtain the optimal order quantity $Q^{*}=136$ units, safety stock $k^{*}=1.31$, reorder point $r^{*}=64$ units, lead time $L=4$ weeks, number of lots (delivered from the manufacturer to the retailer) $m^{*}=3$, backorder rate $\beta^{*}=0.94$, and the minimum expected average cost $\mathrm{ETC}^{N}=\$ 7094$.

We now examine the case when both parties take decisions independently to determine their own optimal policies. When the retailer takes decision independently, his optimal policy is as follows: order quantity $Q_{b}^{*}=112$ units, safety stock $k_{b}^{*}=1.39$, reorder point $r_{b}^{*}=66$ units, lead time $L_{b}^{*}=4$ weeks, backorder rate $\beta^{*}=0.95$, and the minimum expected average cost is $\$ 2735.67$. Also, the manufacturer's optimal production quantity is $m_{v}^{*} Q_{b}^{*}=448$ units and the minimum average cost $\$ 4370.53$. Therefore, when the manufacturer and the retailer do not cooperate with each other, the expected average cost of the supply chain is $\$ 7106$, see Table 5 . However, when both parties cooperate with each other, the expected average cost is $\$ 7094$, which is less than the expected average cost of the supply chain in the decentralized system. From Table 5, we can observe that the retailer's expected average cost in the decentralize model is lower than that of the integrated model, which implies that 


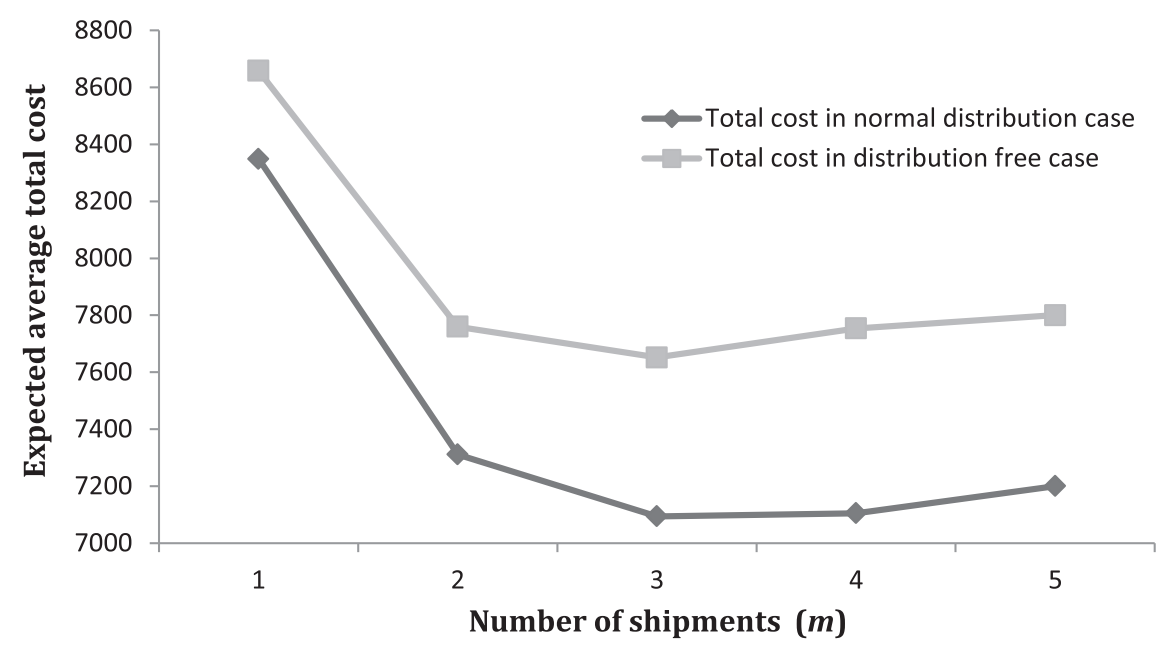

FigURE 4. ETC vs. number of shipments (m).

TABLE 5. Allocation of expected average cost.

\begin{tabular}{|c|c|c|c|c|}
\hline Model type & Retailer & & Manufacturer & \\
\hline \multirow[t]{6}{*}{ Independent } & Order quantity & 112 & Number of shipments & 4 \\
\hline & Lead time (weeks) & 4 & Production quantity & 448 \\
\hline & Safety factor & 1.39 & & \\
\hline & Reorder point & 66 & & \\
\hline & Backorder rate & 0.95 & & \\
\hline & Expected average cost & $\$ 2735.67$ & Average cost & $\$ 4370.53$ \\
\hline \multirow[t]{7}{*}{ Integrated } & Order quantity & 136 & Number of shipments & 3 \\
\hline & Lead time (weeks) & 4 & Production quantity & 408 \\
\hline & Safety factor & 1.31 & & \\
\hline & Reorder point & 64 & & \\
\hline & Backorder rate & 0.94 & & \\
\hline & Expected average cost & $\$ 2789.92$ & Average cost & $\$ 4304.28$ \\
\hline & Allocated average cost & $\$ 2731.00$ & Allocated average cost & $\$ 4363.20$ \\
\hline
\end{tabular}

the retailer may not prefer integrated decision making model unless there is some cost sharing mechanism. Goyal [13] suggested the following method to allocate the expected cost among the retailer and the manufacturer:

Retailer's cost $=\rho \times \operatorname{ETC}^{N}\left(Q^{*}, r^{*}, L^{*}\right)$ and manufacturer's cost $=(1-\rho) \times \operatorname{ETC}^{N}\left(Q^{*}, r^{*}, L^{*}\right)$, where

$$
\rho=\frac{\mathrm{ETC}_{b}\left(Q_{b}^{*}, k_{b}^{*}, L_{b}^{*}\right)}{\operatorname{ETC}_{b}\left(Q_{b}^{*}, k_{b}^{*}, L_{b}^{*}\right)+\operatorname{ETC}_{v}\left(Q_{b}^{*} m_{v}^{*}\right)},
$$

The allocated costs for the retailer and the manufacturer are shown in Table 5.

We now investigate the effects of controllable backorder and trade-credit financing on the average costs of the manufacturer and the retailer. In Table 6, we compare the results of our model with those of Ouyang et al. [38] where shortages were fully backlogged and trade-credit financing was not considered. From Table 6 , we observe that the expected average cost of the supply chain is greater than that of the Ouyang et al.'s [38] model by $6.11 \%$. This is due to consideration of variable backorder and trade-credit financing. In our model, the retailer's 
TABLE 6. A comparative study.

\begin{tabular}{lcccc}
\hline \hline & \multicolumn{2}{c}{ Integrated model } & \multicolumn{2}{c}{ Independent model } \\
\cline { 2 - 5 } & Present model & $\begin{array}{c}\text { Ouyang et al. }[38] \\
\left(I_{d}=0, I_{c}=0,\right. \\
\left.I_{v}=0, \alpha=0\right)\end{array}$ & Present model & $\begin{array}{c}\text { Ouyang } \text { et al. }[38] \\
\left(I_{d}=0, I_{c}=0,\right. \\
\left.I_{v}=0, \alpha=0\right)\end{array}$ \\
\hline $\begin{array}{l}\text { Retailer's cost } \\
\text { Manufacturer's cost }\end{array}$ & $\$ 2789.92$ & $\$ 2862.7$ & $\$ 2735.67$ & $\$ 2832.0$ \\
Joint cost & $\$ 7304.28$ & $\$ 3797.7$ & $\$ 4370.53$ & $\$ 3893.9$ \\
$\begin{array}{l}\text { Retailer's } \\
\text { allocated cost }\end{array}$ & $\$ 2731.00$ & $\$ 2804.4$ & $\$ 7106.20$ & $\$ 6725.9$ \\
$\begin{array}{l}\text { Manufacturer's } \\
\text { allocated cost }\end{array}$ & $\$ 4363.20$ & $\$ 3856.0$ & - & - \\
\hline
\end{tabular}

TABLE 7. Optimal results in distribution-free case (Example 6.2).

\begin{tabular}{ccccccc}
\hline \hline$m$ & $L_{m}^{* *}$ & $k_{m}^{* *}$ & $R_{m}^{* *}$ & $Q_{m}^{* *}$ & $\beta_{m}^{* *}$ & $\operatorname{ETC}^{N}\left(Q_{m}^{* *}, k_{m}^{* *}, L_{m}^{* *}, m\right)$ \\
\hline 1 & 3 & 1.16 & 49 & 271 & 0.82 & $\$ 8658$ \\
2 & 3 & 1.44 & 52 & 184 & 0.84 & $\$ 7760$ \\
$\mathbf{3}$ & $\mathbf{3}$ & $\mathbf{1 . 6 2}$ & $\mathbf{5 4}$ & $\mathbf{1 4 6}$ & $\mathbf{0 . 8 5}$ & $\$ \mathbf{7 6 5 2}$ \\
4 & 3 & 1.77 & 56 & 124 & 0.86 & $\$ 7754$ \\
\hline
\end{tabular}

Notes. The bold values indicate the optimal solution of the decision variables.

allocated cost which is $60 \%$ of the integrated cost is $3 \%$ more than that of Ouyang et al.'s [38] model. On the other hand, the manufacturer's allocated cost which is $40 \%$ of the integrated cost is $3 \%$ less than that of Ouyang et al.'s [38] model. This indicates that the manufacturer is beneficial in our model.

Example 6.2. In this example, we use the same data as given in Table 1. Applying Algorithm 2, we obtain the results of the model when lead time demand does not follow any specific distribution. The results are given in Table 7.

\subsection{Evaluation of expected value of additional information (EVAI)}

Now, we compare the results of the distribution-free model with those of the normal distribution model. We see from Tables 4 to 10 that, in the normal distribution model, the set of optimal values of the decision variables is $\left(Q^{*}, k^{*}, L^{*}, m^{*}\right)=(136,1.31,4,3)$, and that in the distribution-free model is $\left(Q^{* *}, k^{* *}, L^{* *}, m^{* *}\right)=$ $(146,1.62,3,3)$. If we utilize the solution obtained by the distribution-free approach instead of utilizing the normal distribution model, then the added cost will be $\operatorname{ETC}^{N}\left(Q^{* *}, k^{* *}, L^{* *}, m^{* *}\right)-\operatorname{ETC}^{N}\left(Q^{*}, k^{*}, L^{*}, m^{*}\right)$

$=\operatorname{ETC}^{N}(146,1.62,3,3)-\operatorname{ETC}^{N}(136,1.31,4,3)=7200-7094=\$ 106$. This amount is said to be the expected value of additional information (EVAI) for the retailer that he would be willing to pay to collect the information to know the form of lead time demand distribution.

Additionally, we consider the same problem with negative exponential backorder rate as $\beta=\theta e^{-\epsilon B(r)}$, $B(r)=E(X-r)^{+}$(Lee et al. [26]). Results are given in Table 8.

\section{SENSITIVITY ANALYSIS}

In this section, we perform sensitivity analysis to investigate the effects of the key parameters on the optimal solutions. 
TABLE 8. Summary of results for negative exponential backorder rate.

\begin{tabular}{lcccccc}
\hline \hline$\epsilon$ & $L_{m}^{*}$ & $k_{m}^{*}$ & $R_{m}^{*}$ & $Q_{m}^{*}$ & $\beta_{m}^{*}$ & $\operatorname{ETC}^{N}\left(Q_{m}^{*}, k_{m}^{*}, L_{m}^{*}, m\right)$ \\
\hline 0.00 & 3 & 1.58 & 68 & 136 & 0.97 & $\$ 7208$ \\
2.00 & 3 & 1.78 & 71 & 136 & 0.98 & $\$ 7252$ \\
10.0 & 3 & 1.89 & 73 & 136 & 0.98 & $\$ 7292$ \\
20.0 & 3 & 1.89 & 73 & 136 & 0.98 & $\$ 7303$ \\
40.0 & 3 & 1.87 & 72 & 136 & 0.98 & $\$ 7305$ \\
80.0 & 3 & 1.87 & 72 & 136 & 0.98 & $\$ 7305$ \\
$\infty$ & 3 & 1.87 & 72 & 136 & 0.98 & $\$ 7305$ \\
\hline
\end{tabular}

TABLE 9. Effect of trade-credit period $t_{c}$ on optimal results.

\begin{tabular}{lccccccc}
\hline \hline$t_{c}$ & $m$ & $L_{m}^{*}$ & $k_{m}^{*}$ & $R_{m}^{*}$ & $Q_{m}^{*}$ & $\beta_{m}^{*}$ & $\operatorname{ETC}^{N}\left(Q_{m}^{*}, k_{m}^{*}, L_{m}^{*}, m\right)$ \\
\hline 0.1 & 4 & 4 & 1.40 & 66 & 111 & 0.95 & $\$ 7174$ \\
0.2 & 3 & 4 & 1.31 & 64 & 136 & 0.94 & $\$ 7094$ \\
0.3 & 3 & 4 & 1.29 & 64 & 141 & 0.94 & $\$ 7087$ \\
0.4 & 3 & 4 & 1.27 & 64 & 147 & 0.94 & $\$ 7160$ \\
0.5 & 3 & 4 & 1.25 & 64 & 155 & 0.93 & $\$ 7306$ \\
0.6 & 2 & 4 & 1.13 & 62 & 201 & 0.92 & $\$ 7452$ \\
0.7 & 2 & 4 & 1.11 & 62 & 211 & 0.91 & $\$ 7619$ \\
0.8 & 2 & 4 & 1.08 & 61 & 222 & 0.91 & $\$ 7827$ \\
0.9 & 2 & 4 & 1.06 & 61 & 234 & 0.91 & $\$ 8070$ \\
\hline
\end{tabular}

\subsection{Effect of trade-credit period $\left(t_{c}\right)$}

Table 9 presents the effect of credit period $t_{c}$ ranging from 0.1 to 0.9 on optimal solutions. From Table 7 , it is observed that a higher value of credit period increases the retailer's order quantity. Safety factor and reorder point both tend to decrease as credit period increases. Furthermore, the expected average cost of the supply chain tends to decrease for $t_{c} \in[0.1,0.3]$ and increase for $t_{c} \in[0.4,0.9]$. The expected average cost and order quantity are more sensitive for higher value of $t_{c}$, whereas the reorder point and the safety factor are less sensitive to $t_{c}$ (see Figs. 5 and 6 ).

\subsection{Effect of backorder parameter $(\alpha)$}

Table 10 indicates that an increase in the value of $\alpha$ increases the expected average cost whereas it decreases the backorder rate. This is due to the fact that, as shortage quantity becomes more sensitive to backorder parameter $\alpha$, shortage quantity increases resulting an increase in the average cost. Even for small value of $\alpha$, the expected average cost, safety factor, and the reorder point are highly sensitive. When $\alpha$ takes a very high value, the expected average cost represents the lost sale case $($ i.e., $\beta \rightarrow 0$ ), and when $\alpha$ takes a very small value, the expected average cost represents the fully backorder case $($ i.e., $\beta \rightarrow 1)$. However, $\alpha$ has no effect on lead time and number of shipments (see Figs. 7 and 8).

\subsection{Effect of lead time demand standard deviation $(\sigma)$}

We investigate the effect of lead time standard deviation on the optimal results. From Table 11, we see that an increase in the value of $\sigma$ decreases the backorder rate. This is due to the fact that a higher value of $\sigma$ implies higher amount of shortages which decreases the backorder rate. Also, we see that, as $\sigma$ increases, the order quantity and the safety factor also increase. This is because shortages increase for higher value of $\sigma$, which leads 


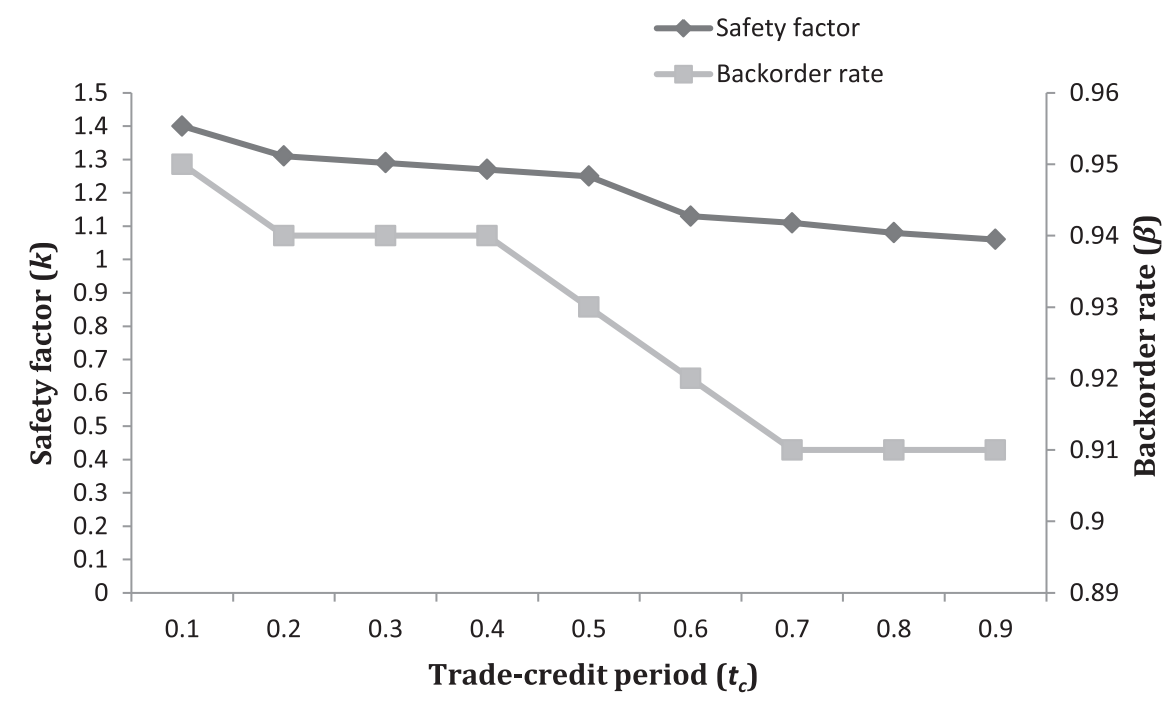

FiguRE 5. Trade-credit period $\left(t_{c}\right)$ vs. safety factor $(k)$ and backorder rate $(\beta)$.

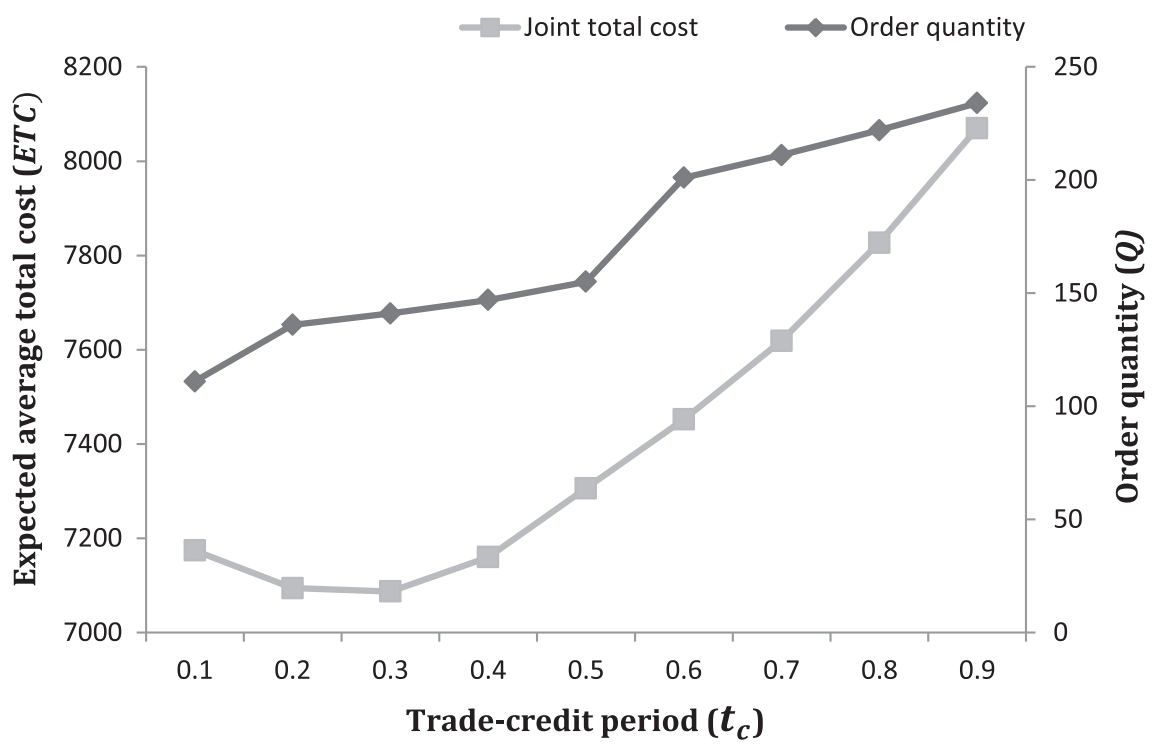

Figure 6. Trade-credit period $\left(t_{c}\right)$ vs. expected average total cost (ETC) and order quality $(Q)$.

to larger order quantity and safety stock. Figures 9 and 10 also indicate that $\sigma$ impacts the expected average cost significantly.

\section{Conclusions}

Customer's demand, replenishment lead time, and time gap between placing and receiving of an order play vital roles in economic order quantity (EOQ) modelling. In most cases, customers do not have patience to wait during shortage period to meet their demands from the next replenishment which results in lost sales. 
TABLE 10. Effect of backorder parameter $\alpha$ on optimal results.

\begin{tabular}{lccccccc}
\hline \hline$\alpha$ & $m$ & $L_{m}^{*}$ & $k_{m}^{*}$ & $R_{m}^{*}$ & $Q_{m}^{*}$ & $\beta_{m}^{*}$ & $\operatorname{ETC}^{N}\left(Q_{m}^{*}, k_{m}^{*}, L_{m}^{*}, m\right)$ \\
\hline 0.00 & 3 & 4 & 1.12 & 62 & 137 & 1.00 & $\$ 7059$ \\
0.50 & 3 & 4 & 1.51 & 67 & 136 & 0.83 & $\$ 7145$ \\
1.00 & 3 & 4 & 1.60 & 68 & 136 & 0.75 & $\$ 7173$ \\
10.0 & 3 & 4 & 1.83 & 72 & 136 & 0.35 & $\$ 7261$ \\
20.0 & 3 & 4 & 1.85 & 72 & 136 & 0.22 & $\$ 7278$ \\
40.0 & 3 & 4 & 1.86 & 72 & 136 & 0.13 & $\$ 7290$ \\
80.0 & 3 & 4 & 1.87 & 72 & 136 & 0.07 & $\$ 7297$ \\
100 & 3 & 4 & 1.87 & 72 & 136 & 0.06 & $\$ 7299$ \\
$\infty$ & 3 & 4 & 1.87 & 72 & 136 & 0.00 & $\$ 7305$ \\
\hline
\end{tabular}

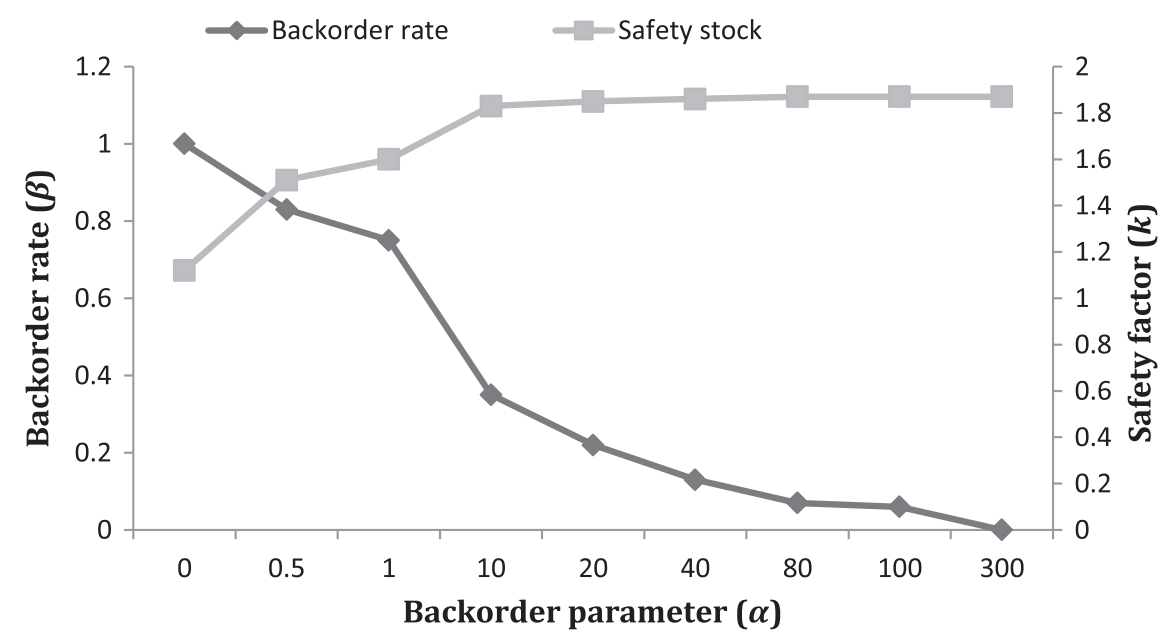

FiguRE 7. Backorder parameter $(\alpha)$ vs. safety factor $(k)$ and backorder rate $(\beta)$.

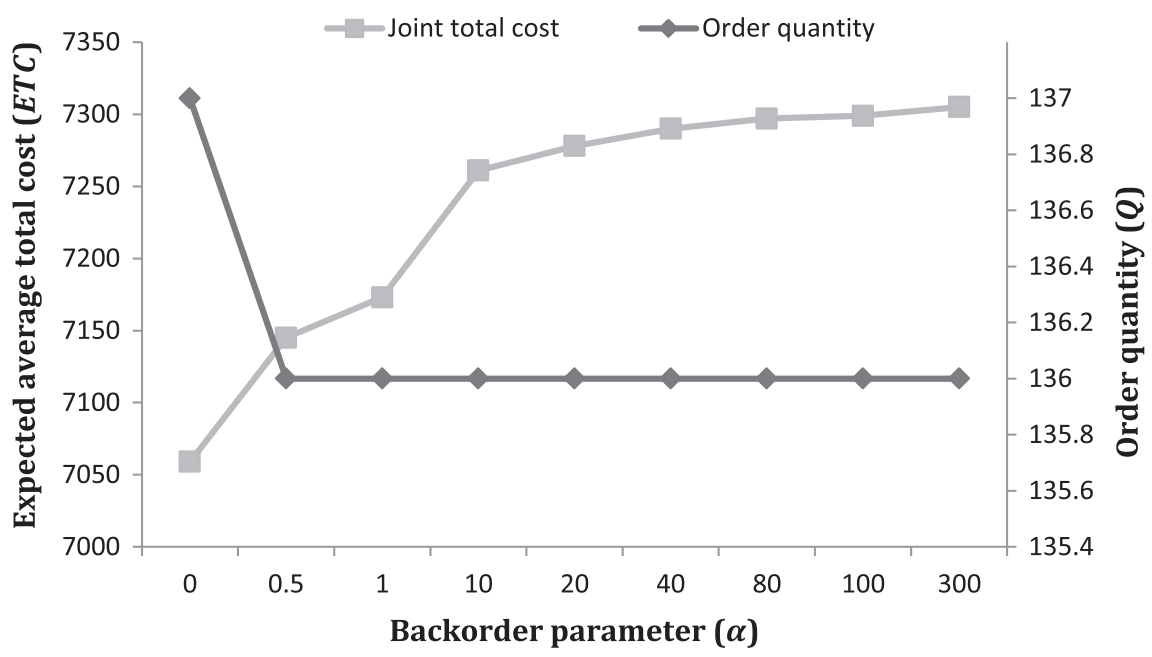

FigURE 8. Backorder parameter $(\alpha)$ vs. expected average total cost (ETC) and order quality $(Q)$. 
TABLE 11. Effect of standard deviation $\sigma$ on optimal results.

\begin{tabular}{cccccccc}
\hline \hline$\sigma$ & $m$ & $L_{m}^{*}$ & $k_{m}^{*}$ & $R_{m}^{*}$ & $Q_{m}^{*}$ & $\beta_{m}^{*}$ & $\operatorname{ETC}^{N}\left(Q_{m}^{*}, k_{m}^{*}, L_{m}^{*}, m\right)$ \\
\hline 1 & 4 & 6 & 1.29 & 72 & 111 & 0.99 & $\$ 6430$ \\
3 & 4 & 6 & 1.34 & 79 & 112 & 0.97 & $\$ 6676$ \\
5 & 3 & 4 & 1.28 & 59 & 135 & 0.95 & $\$ 6896$ \\
7 & 3 & 4 & 1.31 & 64 & 136 & 0.94 & $\$ 7094$ \\
9 & 3 & 4 & 1.34 & 70 & 137 & 0.93 & $\$ 7295$ \\
14 & 3 & 3 & 1.36 & 67 & 141 & 0.91 & $\$ 7762$ \\
20 & 3 & 3 & 1.40 & 83 & 143 & 0.89 & $\$ 8297$ \\
\hline
\end{tabular}

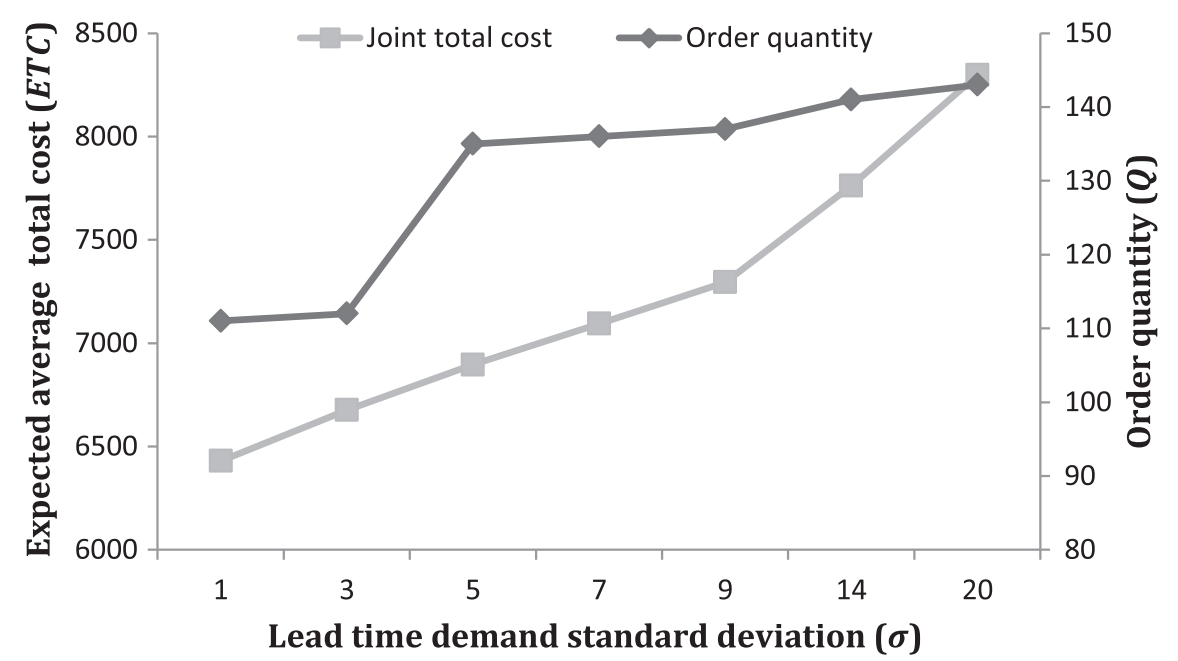

FiguRE 9. Lead time standard deviation $(\sigma) v s$. expected average total cost (ETC) and order quality $(Q)$.

Consequently, partial backordering rate varies with replenishment lead time. Moreover, a larger lead time creates a negative impression that reduces customers' demand. The aim of this paper was to determine the inventory policy when a system faces lead time dependent backlogging rate along with stochastic lead time demand. To investigate the problem, an integrated manufacturer-retailer supply chain model is considered where the market demand is uncertain, shortages are partially backlogged, and the lead time is controllable. Also, a trade credit period offered by the manufacturer to the retailer is incorporated. To reduce the replenishment lead time, we have decomposed the lead time into several components with normal and minimum durations having different crashing costs for reducing to a specified minimum duration. First, we have formulated the model considering known lead time demand distribution and then studied extensively for unknown distribution case. A comparative study on the results of non-integrated approach and integrated approach is conducted. The proposed model can be utilized to different kinds of firms, such as electronic assembling frameworks, the garments fabricating industries, food industries and so on.

The results of the paper indicate that, in case when lead time demand deviation is high, choosing lead time reduction strategy may reduce the total expected system cost. Further, it is seen that the increment of lead time dependency parameter shifts the model to full lost sale case where expected total cost is maximum. Cases with smaller lead time demand deviation may be interpreted as a restriction on the invest amount on lead time reduction. In such a situation, a company may search for cost-optimal solutions without investing in lead 


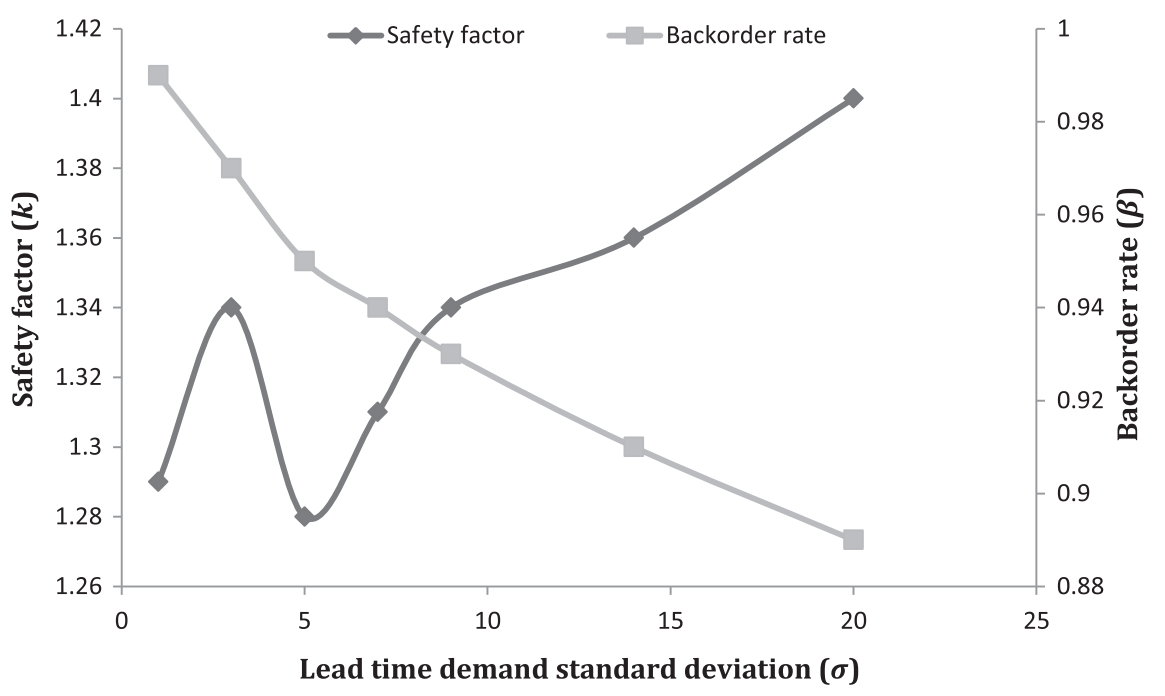

FiguRE 10. Lead time standard deviation $(\sigma)$ vs. safety factor $(k)$ and backorder rate $(\beta)$.

time reduction. Accordingly, it can be seen that trade credit offer increases the order quantity which helps in establishing coordination between the supply chain players.

One limitation of our work is clearly the consideration of single manufacturer single retailer situation, which restricts its applicability to industries. Future research may focus on studying some other backorder rate functions (e.g., exponential) in a multiple sourcing environment. One can consider imperfect production and investment in quality improvement to extend the present work. Further, the entire replenishment lead time can be taken as an addition of different lead time components (e.g., setup time, production time, transportation time, etc.) and investment can be made to reduce a specific component (Glock [12]).

\section{Appendix A. Proof of Proposition 5.1}

The expected average cost for normally distributed lead time demand is

$$
\begin{aligned}
\operatorname{ETC}^{N}(Q, k, L, m)= & \frac{D}{Q}[G(m)+C(L)]+c_{b}\left(r_{b}+I_{c}\right) k \sigma \sqrt{L}+\frac{Q}{2} H(m) \\
& +\left\{\frac{D}{Q}\left(\pi-\frac{c_{s} t_{c} I_{d}}{1+\alpha \sigma \sqrt{L} \Psi(k)}\right)+\frac{\alpha \sigma \sqrt{L} \Psi(k) M(Q)}{1+\alpha \sigma \sqrt{L} \Psi(k)}\right\} \sigma \sqrt{L} \Psi(k) \\
& +\frac{\left(Q-D t_{c}\right)^{2} c_{b} I_{c}}{2 Q}-\frac{D^{2} t_{c}^{2} c_{s} I_{d}}{2 Q}+I_{v} c_{b} t_{c} D .
\end{aligned}
$$

For fixed $m$, taking the first order partial derivative of $\operatorname{ETC}^{N}(Q, k, L, m)$ with respect to $L \in\left[L_{i}, L_{i-1}\right]$ we have

$$
\begin{aligned}
\frac{\partial \mathrm{ETC}^{N}}{\partial L}= & \frac{c_{b}\left(r_{b}+I_{c}\right) k \sigma L^{-1 / 2}}{2}+M(Q) \frac{(2+v) v^{2}}{2 \alpha L(1+v)^{2}} \\
& +\frac{D v}{2 \alpha L Q}\left\{\pi-\frac{c_{s} t_{c} I_{d}}{(1+v)^{2}}\right\}-\frac{D}{Q} c_{i} .
\end{aligned}
$$


The second order derivative of $\operatorname{ETC}^{N}(Q, k, L, m)$ with respect to $L \in\left[L_{i}, L_{i-1}\right]$ is

$$
\begin{aligned}
\frac{\partial \mathrm{ETC}^{N}}{\partial L^{2}}= & -\frac{1}{4} c_{b}\left(r_{b}+I_{c}\right) k \sigma L^{-3 / 2}-M(Q) \frac{(3+v) v^{3}}{4 \alpha L^{2}(1+v)^{3}} \\
& -\frac{D \pi v}{4 \alpha L^{2} Q}\left\{\pi-\frac{c_{s} t_{c} I_{d}(1+3 v)}{(1+v)^{3}}\right\}<0 \\
\quad \text { if } L< & \left(\frac{\sqrt{\pi c_{s} t_{c} I_{d}}-\pi}{\pi \alpha \sigma \Psi(k)}\right)^{2} .
\end{aligned}
$$

Hence, $\operatorname{ETC}^{N}(Q, k, L, m)$ is concave in $L \in\left[L_{i}, L_{i-1}^{\prime}\right]$ where $L_{i-1}^{\prime}=\min \left\{L_{i-1},\left(\frac{\sqrt{\pi c_{s} t_{c} I_{d}}-\pi}{\pi \alpha \sigma \Psi(k)}\right)^{2}\right\}$. Therefore, Proposition 5.1 is proved.

\section{Appendix B. Proof of Proposition 5.2}

For fixed $m$ and $L \in\left[L_{i}, L_{i-1}\right]$, taking first and second order partial derivatives of $\operatorname{ETC}^{N}(Q, k, L, m)$ with respect to $Q$ and $k$, we have

$$
\begin{aligned}
\frac{\partial \mathrm{ETC}^{N}}{\partial Q}= & -\frac{D}{Q^{2}}[G(m)+C(L)]-\frac{D^{2} t_{c}^{2} c_{b} I_{c}}{2 Q^{2}}+\frac{D^{2} t_{c}^{2} c_{s} I_{d}}{2 Q^{2}} \\
& -\frac{D v}{\alpha Q^{2}}\left\{\bar{\pi}-\frac{c_{s} t_{c} I_{d}}{1+v}\right\}+\frac{H(m)}{2} \\
\frac{\partial \mathrm{ETC}^{N}}{\partial k}= & c_{b}\left(r_{b}+I_{c}\right) \sigma \sqrt{L}+\alpha \sigma^{2} L \Psi(k) \lambda(k)\left\{\frac{2+v}{(1+v)^{2}}\right\} M(Q) \\
& +\frac{D \lambda(k) \sigma \sqrt{L}}{Q}\left(\pi-\frac{c_{s} t_{c} I_{d}}{(1+v)^{2}}\right) \\
\frac{\partial^{2} \mathrm{ETC}^{N}}{\partial Q^{2}}= & \frac{2 D}{Q^{3}}\left[G(m)+C(L)+\sigma \sqrt{L} \Psi(k)\left\{\bar{\pi}-\frac{c_{s} t_{c} I_{d}}{1+v}\right\}\right] \\
& +\frac{D^{2} t_{c}^{2}}{Q^{3}}\left(c_{b} I_{c}-c_{s} I_{d}\right)>0 \text { if } I_{c}>\frac{c_{s} I_{d}}{c_{b}} \text { and } \Psi(k)>\frac{c_{s} t_{c} I_{d}}{\pi_{0} \alpha \sigma \sqrt{L}} \\
\frac{\partial^{2} \mathrm{ETC}^{N}}{\partial k^{2}}= & \left(r_{b}+I_{c}\right) c_{b}\left(\frac{v \sigma \sqrt{L} \phi(k)(2+v)}{(1+v)^{2}}\right)+\frac{2 \alpha \sigma^{2} L[\Phi(k)-1]^{2}}{(1+v)^{3}} \\
& \left\{\frac{D}{Q}\left(\pi_{0}+c_{s} t_{c} I_{d}\right)+c_{b}\left(I_{c}+r_{b}\right)\right\}+\frac{D \sigma \sqrt{L} \phi(k)}{Q} \\
& \left(\bar{\pi}+\frac{\pi_{0} v}{(1+v)^{2}}-\frac{c_{s} t_{c} I_{d}}{(1+v)^{2}}\right)>0 \text { if } \Psi(k)>\frac{c_{s} t_{c} I_{d}}{\pi_{0} \alpha \sigma \sqrt{L}}
\end{aligned}
$$

where $\bar{\pi}=\pi+\frac{\pi_{0} v}{1+v}, \lambda(k)=\Phi(k)-1, v=\alpha \sigma \sqrt{L} \Psi(k)$.

From (B.3) and (B.4), we can say that if $I_{c}>\frac{c_{s} I_{d}}{c_{b}}, \operatorname{ETC}^{N}(Q, k, L, m)$ is convex in $Q$ and $k$ for all $Q>0$ and $k>0$ such that $\Psi(k)>\frac{c_{s} t_{c} I_{d}}{\pi_{0} \alpha \sigma \sqrt{L}}$. Hence Proposition 5.2 is proved. 


\section{Appendix C. Proof of Proposition 5.3}

For convexity of the cost function given in (5.3), the Hessian matrix for $\operatorname{ETC}^{N}(Q, k, L, m)$ must be positive definite. The Hessian matrix is given by

$$
\mathbf{H}=\left[\begin{array}{ll}
\frac{\partial^{2} \operatorname{ETC}^{N}(\cdot)}{\partial Q^{2}} & \frac{\partial^{2} \operatorname{ETC}^{N}(\cdot)}{\partial Q \partial k} \\
\frac{\partial^{2} \operatorname{ETC}^{N}(\cdot)}{\partial k \partial Q} & \frac{\partial^{2} \operatorname{ETC}^{N}(\cdot)}{\partial k^{2}}
\end{array}\right]
$$

where $\frac{\partial^{2} \mathrm{ETC}^{N}(\cdot)}{\partial Q^{2}}$ and $\frac{\partial^{2} \mathrm{ETC}^{N}(\cdot)}{\partial k^{2}}$ are given in (B.3) and (B.4), and

$$
\frac{\partial^{2} \mathrm{ETC}^{N}}{\partial Q \partial k}=\frac{\partial^{2} \mathrm{ETC}^{N}}{\partial k \partial Q}=\frac{D \sigma \sqrt{L}[1-\Phi(k)]}{Q^{2}}\left[\bar{\pi}+\frac{\pi_{0} v}{(1+v)^{2}}-\frac{c_{s} t_{c} I_{d}}{(1+v)^{2}}\right]
$$

Now

$$
\begin{aligned}
& |H|=\frac{\partial^{2} \operatorname{ETC}^{N}(\cdot)}{\partial Q^{2}} \times \frac{\partial^{2} \operatorname{ETC}^{N}(\cdot)}{\partial k^{2}}-\left[\frac{\partial^{2} \operatorname{ETC}^{N}(\cdot)}{\partial Q \partial k}\right]^{2} \\
& =\left\{\frac{2 D}{Q^{3}}\left[G(m)+C(L)+\sigma \sqrt{L} \Psi(k)\left\{\bar{\pi}-\frac{c_{s} t_{c} I_{d}}{1+v}\right\}\right]+\frac{D^{2} t_{c}^{2}}{Q^{3}}\left(c_{b} I_{c}-c_{s} I_{d}\right)\right\} \\
& \times\left\{\left(r_{b}+I_{c}\right) c_{b}\left(\frac{v \sigma \sqrt{L} \phi(k)(2+v)}{(1+v)^{2}}\right)+\frac{2 \alpha \sigma^{2} L[\Phi(k)-1]^{2}}{(1+v)^{3}}\left\{\frac{D}{Q}\left(\pi_{0}+c_{s} t_{c} I_{d}\right)+c_{b}\left(I_{c}+r_{b}\right)\right\}\right. \\
& \left.+\frac{D \sigma \sqrt{L} \phi(k)}{Q}\left(\bar{\pi}+\frac{\pi_{0} v}{(1+v)^{2}}-\frac{c_{s} t_{c} I_{d}}{(1+v)^{2}}\right)\right\}-\left\{\frac{D \sigma \sqrt{L}[1-\Phi(k)]}{Q^{2}}\left[\bar{\pi}+\frac{\pi_{0} v}{(1+v)^{2}}-\frac{c_{s} t_{c} I_{d}}{(1+v)^{2}}\right]\right\}^{2} \\
& >\frac{2 D}{Q^{3}} \sigma \sqrt{L} \Psi(k)\left\{\bar{\pi}-\frac{c_{s} t_{c} I_{d}}{1+v}\right\} \frac{D \sigma \sqrt{L} \phi(k)}{Q}\left(\bar{\pi}+\frac{\pi_{0} v}{(1+v)^{2}}-\frac{c_{s} t_{c} I_{d}}{(1+v)^{2}}\right) \\
& -\left\{\frac{D \sigma \sqrt{L}[1-\Phi(k)]}{Q^{2}}\left[\bar{\pi}+\frac{\pi_{0} v}{(1+v)^{2}}-\frac{c_{s} t_{c} I_{d}}{(1+v)^{2}}\right]\right\}^{2} \text { (after deleting the positive terms) } \\
& =\frac{2 D^{2} \sigma^{2} L \phi(k) \Psi(k)}{Q^{4}}\left(\bar{\pi}-\frac{c_{s} t_{c} I_{d}}{1+v}\right)\left(\bar{\pi}+\frac{\pi_{0} v}{(1+v)^{2}}-\frac{c_{s} t_{c} I_{d}}{(1+v)^{2}}\right) \\
& -\frac{D^{2} \sigma^{2} L[1-\Phi(k)]^{2}}{Q^{4}}\left(\bar{\pi}+\frac{\pi_{0} v}{(1+v)^{2}}-\frac{c_{s} t_{c} I_{d}}{(1+v)^{2}}\right)^{2} \\
& =\frac{2 D^{2} \sigma^{2} L \phi(k) \Psi(k)}{Q^{4}}\left(\bar{\pi}+\frac{\pi_{0} v}{(1+v)^{2}}-\frac{c_{s} t_{c} I_{d}}{(1+v)^{2}}\right)\left(\bar{\pi}+\frac{\pi_{0} v}{(1+v)^{2}}-\frac{c_{s} t_{c} I_{d}}{(1+v)^{2}}\right) \\
& -\frac{2 D^{2} \sigma^{2} L \phi(k) \Psi(k)}{Q^{4}}\left(\frac{\pi_{0} v}{(1+v)^{2}}-\frac{c_{s} t_{c} I_{d}}{(1+v)^{2}}+\frac{c_{s} t_{c} I_{d}}{1+v}\right)\left(\bar{\pi}+\frac{\pi_{0} v}{(1+v)^{2}}-\frac{c_{s} t_{c} I_{d}}{(1+v)^{2}}\right) \\
& -\frac{D^{2} \sigma^{2} L[1-\Phi(k)]^{2}}{Q^{4}}\left(\bar{\pi}+\frac{\pi_{0} v}{(1+v)^{2}}-\frac{c_{s} t_{c} I_{d}}{(1+v)^{2}}\right)^{2} \\
& <\frac{2 D^{2} \sigma^{2} L \phi(k) \Psi(k)}{Q^{4}}\left(\bar{\pi}+\frac{\pi_{0} v}{(1+v)^{2}}-\frac{c_{s} t_{c} I_{d}}{(1+v)^{2}}\right)^{2} \\
& +\frac{2 D^{2} \sigma^{2} L \phi(k) \Psi(k)}{Q^{4}}\left(\frac{c_{s} t_{c} I_{d}}{(1+v)^{2}}\right)\left(\bar{\pi}+\frac{\pi_{0} v}{(1+v)^{2}}-\frac{c_{s} t_{c} I_{d}}{(1+v)^{2}}\right) \\
& -\frac{D^{2} \sigma^{2} L[1-\Phi(k)]^{2}}{Q^{4}}\left(\bar{\pi}+\frac{\pi_{0} v}{(1+v)^{2}}-\frac{c_{s} t_{c} I_{d}}{(1+v)^{2}}\right)^{2} \quad \text { (after deleting the negative terms) }
\end{aligned}
$$




$$
\begin{aligned}
> & \frac{2 D^{2} \sigma^{2} L \phi(k) \Psi(k)}{Q^{4}}\left(\bar{\pi}+\frac{\pi_{0} v}{(1+v)^{2}}-\frac{c_{s} t_{c} I_{d}}{(1+v)^{2}}\right)^{2} \\
& -\frac{D^{2} \sigma^{2} L[1-\Phi(k)]^{2}}{Q^{4}}\left(\bar{\pi}+\frac{\pi_{0} v}{(1+v)^{2}}-\frac{c_{s} t_{c} I_{d}}{(1+v)^{2}}\right)^{2} \text { (after deleting the positive terms) } \\
= & \frac{2 D^{2} \sigma^{2} L \phi(k) \Psi(k)}{Q^{4}}\left(\bar{\pi}+\frac{\pi_{0} v}{(1+v)^{2}}-\frac{c_{s} t_{c} I_{d}}{(1+v)^{2}}\right)^{2}\left\{2 \phi(k) \Psi(k)-[\Phi(k)-1]^{2}\right\} \\
> & 0,
\end{aligned}
$$

because $\phi(k)>0, \Psi(k)>0$ and $2 \phi(k) \Psi(k)-[\Phi(k)-1]^{2}>0$, for all $k>0$ (see Ouyang et al. [37]). Therefore, if the Hessian matrix for $\operatorname{ETC}^{N}(Q, k, L, m)$ is positive definite then there exists a unique optimal solution which can be obtained from the first order necessary conditions $\frac{\partial \mathrm{ETC} C^{N}}{\partial Q}=0$ and $\frac{\partial \mathrm{ETC}}{\partial k}=0$ as

$$
\begin{aligned}
& Q=\sqrt{\frac{2 D[G(m)+\sigma \sqrt{L} \Psi(k) \Delta(k, L)+C(L)]+F_{1}}{F_{2}+H(m)}}, \\
& k=\Phi^{-1}\left(1-\frac{F_{2}[V(k, L)]^{2} Q}{v(k, L) Q M(Q)[1+V(k, L)]+D \pi[V(k, L)]^{2}-D s t_{c} I_{d}}\right)
\end{aligned}
$$

where $F_{1}=D^{2} t_{c}^{2}\left(c_{b} I_{c}-c_{s} I_{d}\right), F_{2}=c_{b}\left(r_{b}+I_{c}\right), \Delta(k, L)=\bar{\pi}-\frac{c_{s} t_{c} I_{d}}{1+v(k, L)}, V(k, L)=1+v(k, L)$.

Hence the proposition is proved.

Acknowledgements. The authors are grateful to the Editor-in-Chief and anonymous referees for their valuable comments and suggestions on an earlier version of this paper. The first author's work is supported by JU-RUSA 2.0 Doctoral Scholarship, Jadavpur University, Kolkata, India under Ref. No. R-11/197/2019.

\section{REFERENCES}

[1] S.P. Aggarwal and C.K. Jaggi, Ordering policies of deteriorating items under permissible delay in payments. J. Oper. Res. Soc. 46 (1995) 658-662.

[2] A. Arkan and S.R. Hejazi, Coordinating orders in a two echelon supply chain with controllable lead time and ordering cost using the credit period. Comput Indus. Eng. 62 (2012) 56-69.

[3] A. Banerjee, A joint economic-lot-size model for purchaser and vendor. Deci. Sci. 17 (1986) 292-311.

[4] M. Ben-Daya and A. Raouf, Inventory models involving lead time as a decision variable. J. Oper. Res. Soc. 45 (1994) $579-582$.

[5] M. Braglia, D. Castellano and D. Song, Distribution-free approach for stochastic Joint-Replenishment Problem with backorderslost sales mixtures, and controllable major ordering cost and lead times. Comput. Oper. Res. 79 (2017) $161-173$.

[6] M. Braglia, D. Castellano, L. Marrazzini and D. Song, A continuous review, $(Q, r)$ inventory model for a deteriorating item with random demand and positive lead time. Comput. Oper. Res. 109 (2019) 102-121.

[7] L.H. Chen and F.S. Kang, Coordination between vendor and buyer considering trade-credit and items of imperfect quality. Int. J. Prod. Econ. 123 (2010) 52-61.

[8] K.J. Chung and T.S. Huang, The optimal retailer's ordering policies for deteriorating items with limited storage capacity under trade-credit financing. Int. J. Prod. Econ. 106 (2007) 127-145.

[9] G. Gallego and I. Moon, The distribution free newsboy problem: review and extensions, J. Oper. Res. Soc. 44 (1993) $825-834$.

[10] I. Giannoccaro and P. Pontrandolfo, Supply chain coordination by revenue sharing contracts. Int. J. Prod. Econ. 89 (2004) $131-139$.

[11] B.C. Giri and B. Roy, A single-manufacturer multi-buyer supply chain inventory model with controllable lead time and pricesensitive demand. J. Indus. Prod. Eng. 32 (2015) 516-527.

[12] C.H. Glock, Lead time reduction strategies in a single-vendor-single-buyer integrated inventory model with lot size-dependent lead times and stochastic demand. Int. J. Prod. Econ. 136 (2012) 37-44.

[13] S.K. Goyal, An integrated inventory model for a single supplier-single customer problem. Int. J. Prod. Res. 15 (1976) $107-111$.

[14] S.K. Goyal, Economic order quantity under conditions of permissible delay in payments. J. Oper. Res. Soc. 36 (1985) $335-338$.

[15] S.K. Goyal, A joint economic-lot-size model for purchaser and vendor: a comment. Deci. Sci. 19 (1988) $236-241$.

[16] D. Ha and S.L. Kim, Implementation of JIT purchasing: an integrated approach. Prod. Plan. Control 18 (1997) $152-157$. 
[17] J. Heydari, P. Zaabi-Ahmadi and T.M. Choi, Coordinating supply chains with stochastic demand by crashing lead times. Comput. Oper. Res. 100 (2018) 394-403.

[18] C.K. Huang, An integrated inventory model under conditions of order processing cost reduction and permissible delay in payments. Appl. Math. Model. 34 (2010) 1352-1359.

[19] J.K. Jha and K. Shanker, Two-echelon supply chain inventory model with controllable lead time and service level constraint. Comput. Indus. Eng. 57 (2009) 1096-1104.

[20] J.K. Jha and K. Shanker, Single-vendor multi-buyer integrated production-inventory model with controllable lead time and service level constraints. Appl. Math. Model. 37 (2013) 1753-1767.

[21] E. Katok and D.Y.Wu, Contracting in supply chains: a laboratory investigation. Manage. Sci. 55 (2009) $1953-1968$.

[22] R.S. Kumar and A. Goswami, A continuous review production-inventory system in fuzzy random environment: minmax distribution free procedure, Comp. Ind. Eng. 79 (2015) 65-75.

[23] S.J. Kim, B. Sarkar and S. Sarkar, An inventory model with backorder price discount and stochastic lead time. DJ J. Eng. Appl. Math. 42 (2019) 34-48.

[24] B.G. Kingsman, The effect of payment rules on ordering and stockholding in purchasing. J. Oper. Res. Soci. 34 (1983) 1085-1098.

[25] W.C. Lee, Inventory model involving controllable backorder rate and variable lead time demand with the mixtures of distribution. Appl. Math. Comput. 160 (2005) 701-717.

[26] W.C. Lee, J.W. Wu and J.W. Hsu, Computational algorithm for inventory model with a service level constraint, lead time demand with the mixture of distributions and controllable negative exponential backorder rate. Appl. Math. Comput. 175 (2006) $1125-1138$.

[27] Y. Li, X. Xu and F. Ye, Supply chain coordination model with controllable lead time and service level constraint. Comput. Indus. Eng. 61 (2011) 858-864.

[28] G. Li, X. Guan, M. Liu and M. Shan, Two-echelon inventory model with service level constraint and controllable lead time sensitive to order quantity. J. Cent. South Univ. 20 (2013) 3324-3333.

[29] C.J. Liao and C.H. Shyu, An analytical determination of lead time with normal demand. Int. J. Oper. Prod. Manage. 11 (1991) $72-78$.

[30] B.N. Mandal and S. Phaujdar, Some EOQ models under permissible delay in payments. Int. J. Manage. Syst. 5 (1989) 99-108.

[31] P. Mandal and B.C. Giri, A single-vendor multi-buyer integrated model with controllable lead time and quality improvement through reduction in defective items. Int. J. Syst. Sci. Oper. Logist. 2 (2015) 1-14.

[32] U. Mishra, An inventory model for Weibull deterioration with stock and price dependent demand. Int. J. Appl. Comput. Math. 3 (2017) 1951-1967.

[33] U. Mishra and C. K. Tripathy, An inventory model for Weibull deteriorating items with salvage value. Int. J. Logist. Syst. Manage. 22 (2015) 67-76.

[34] U. Mishra , J. Tijerina-Aguilera, S. Tiwari and L.E. Cárdenas-Barrón, Retailer's joint ordering, pricing, and preservation technology investment policies for a deteriorating item under permissible delay in payments. Math. Probl. Eng. 2018 (2018) $1-14$.

[35] L.Y. Ouyang and K.S. Wu, Mixture inventory model involving variable lead time with a service level constraint. Comput. Oper. Res. 24 (1997) 875-882.

[36] L.Y. Ouyang and B.R. Chuang, Mixture of inventory model involving variable lead time and controllable backorder rate. Comput. Indus. Eng. 40 (2001) 339-348.

[37] L.Y. Ouyang, N.C. Yeh and K.S. Wu, Mixture inventory model with backorders and lost sales for variable lead time. J. Oper. Res. Soc. 47 (1996) 829-832.

[38] L.Y. Ouyang, K.S. Wu and C.H. Ho, Integrated vendor-buyer cooperative models with stochastic demand in controllable lead time. Int. J. Prod. Econ. 92 (2004) 255-266.

[39] L.Y. Ouyang, K.S. Wu and C.H. Ho, An integrated vendor-buyer inventory model with quality improvement and lead time reduction. Int. J. Prod. Econ. 108 (2007) 349-358.

[40] J.C.H. Pan and J.S. Yang, A study of an integrated inventory with controllable lead time. Int. J. Prod. Res. 40 (2002) 1263-1273.

[41] S. Sarkar and B.C. Giri, Stochastic supply chain model with imperfect production and controllable defective rate. Int. J. Syst. Sci. Oper. Logist. 7 (2018) 133-146.

[42] S. Sarkar and B.C. Giri, A vendor-buyer integrated inventory system with variable lead time and uncertain market demand. Oper. Res. 20 (2020) 491-515.

[43] S. Sarkar, B.C. Giri and A.K. Sarkar, A vendor-buyer inventory model with lot-size and production rate dependent lead time under time value of money. RAIRO: OR. 54 (2020) 961-979

[44] B. Sarkar, B. Mandal and S. Sarkar, Quality improvement and backorder price discount under controllable lead time in an inventory model. J. Manuf. Syst. 35 (2015) 26-36.

[45] S. Tiwari, H.M. Wee and S. Sarkar, Lot-sizing policies for defective and deteriorating items with time-dependent demand and trade credit. Euro. J. Indus. Eng. 11 (2017) 683-703.

[46] Z.K. Weng, Modeling quantity discounts under general price-sensitive demand functions: optimal policies and relationships. Euro. J. Oper. Res. 86 (1995) 300-314.

[47] K.S. Wu, $(Q ; r)$ Inventory model with variable lead time when the amount received is uncertain. J. Inf. Manage. Sci. 11 (2000) $81-94$. 
[48] K.S. Wu, L.Y. Ouyang and C.H. Ho, Integrated vendor-buyer inventory system with sub lot sampling inspection policy and controllable lead time. Int. J. Syst. Sci. 38 (2007) 339-350.

[49] J.S. Yang and J.C. Pan, Just-in-time purchasing: an integrated inventory model involving deterministic variable lead time and quality improvement investment. Int. J. Prod. Res. 42 (2004) 853-863.

[50] J.Q. Yang, X.M. Zhang, H. Fu and C. Liu, Inventory competition in a dual-channel supply chain with delivery lead time consideration. Appl. Math. Model. 42 (2017) 675-692.

[51] C. Zikopoulos, Remanufacturing lot sizing with stochastic lead-time resulting from stochastic quality of returns. Int. J. Prod. Res. 55 (2017) 1565-1587. 